\title{
Studying the consequences of literacy within a literate society: The cognitive correlates of print exposure
}

\author{
KEITH E. STANOVICH \\ Ontario Institute for Studies in Education, Toronto, Ontario, Canada \\ and \\ ANNE E. CUNNINGHAM \\ University of California, Berkeley, California
}

\begin{abstract}
Most studies of the cognitive consequences of literacy have attempted to compare the performance of literate individuals with that of illiterate individuals. We argue that it is not absolutely necessary to examine illiterates in order to study the cognitive consequences of reading experience because there is enormous variation in exposure to print even within a generally literate society. In the present study, we tested several methods of assessing differential exposure to print and demonstrated that all have significant correlations with measures of vocabulary, cultural knowledge, spelling ability, and verbal fluency. Several indicators of print exposure predicted variance in these knowledge domains even when general ability and reading-comprehension skill were statistically controlled. Our results, although correlational, suggest that print exposure is an independent contributor to the development of certain verbal skills.
\end{abstract}

Researchers studying the cognitive psychology of reading have attempted to specify individual differences in the cognitive processes that support efficient reading performance (Carr \& Levy, 1990; Daneman, 1991; Just \& Carpenter, 1987; Perfetti, 1985; Rayner \& Pollatsek, 1989). A popular research strategy has been the cognitivecorrelates approach (see Pellegrino \& Glaser, 1979; Sternberg, 1990), in which investigators attempt to determine whether individual differences in particular cognitive processes or knowledge bases can serve as predictors of reading ability (e.g., Jackson \& McClelland, 1979). Implicit in such analyses is the assumption that differences in cognitive processes are causally prior to individual differences in any overt reading behavior.

In cognitive psychology, very little attention has been focused on what might be considered a form of reciprocal causation-that is, on the possibility that differences in exposure to print affect the development of cognitive processes and declarative knowledge bases. In contrast, anthropologists, sociologists, and historians have for decades been intensely preoccupied with speculations on how the exercise of literacy affects knowledge acquisition, belief systems, cognitive processes, and reasoning. The literature on the cognitive consequences of literacy

\footnotetext{
The authors wish to thank Elisa Salasin and Cheryl Anderson for assistance in data collection. The participation of the second author was funded by a Spencer Fellowship from the National Academy of Education. Requests for reprints should be sent to Keith E. Stanovich, Ontario Institute for Studies in Education, 252 Bloor Street West, Toronto, ON, Canada M5S 1V6.
}

in the humanities and social sciences outside of psychology is large and steadily growing (Gee, 1988; Goody, 1977, 1987; Graff, 1986, 1987; Havelock, 1963, 1980; Kaestle, 1991; Olson, 1977, 1987, 1988; Ong. 1967, 1982; Stock, 1983).

It is not at all clear why the division of labor between cognitive psychologists and other social scientists in the domain of literacy should have developed in such an extreme fashion. Reading is a very special type of interface with the environment, providing the organism with unique opportunities to acquire declarative knowledge. Furthermore, the processing mechanisms exercised during reading receive an unusual amount of practice. Certain microprocesses of reading that are linked to words or groups of words are repeatedly exercised. From the time of at least the fifth grade, an avid reader is seeing literally millions of words a year (Anderson, Wilson, \& Fielding, 1988). Thus, whatever cognitive processes are engaged over word or word-group units (phonological coding, semantic activation, parsing, induction of new vocabulary items) are being exercised hundreds of times a day. It is surely to be expected that this amount of cognitive muscleflexing will have some specific effects. Yet, the dominant framework in the cognitive psychology of reading continues to be the cognitive-correlates approach, with its bias toward viewing cognitive processes as causally prior to the reading act, which is almost exclusively conceived as an outcome variable. The present study reverses this pattern by examining the extent to which differences in the exercise of reading skills may be viewed as causally prior to certain cognitive outcomes. 
To put our methodology in context, it is necessary to reiterate an issue that recurs in discussions of the cognitive consequences of literacy in disciplines outside of psychology. In this literature, an important distinction is made between the indirect, mediated effects of literacy - habits of thought derived through cultural immersion in a literate society - and the direct, nonmediated effects of literacy on a particular individual's cognitive processes and knowledge structures (see Goody, 1987; Scribner \& Cole, 1978). For example, illiterates, or people who engage only marginally in literacy activities, may derive certain cognitive benefits from participation in a literate culture. These have been termed the mediated effects of literacy (see Goody, 1987, pp. 217-252), and much work by anthropologists and historians has sought to assess these culturally mediated consequences of literacy.

In contrast, the cognitive psychologist seeks to explicate the individual effects of having personally engaged in reading/writing activities (Scribner \& Cole, 1978, 1981). However, the existence of mediated, or indirect, effects of living in a literate society sometimes makes it difficult to assess the direct effects of exposure to print. For example, several theorists have linked the acquisition of literacy to processes such as logical reasoning and decontextualized thinking (Greenfield, 1972; Olson, 1977, 1986; Ong, 1982; Scinto, 1986; Scribner \& Cole, 1978). In these domains, the likelihood of mediated effects seems particularly high. With regard to general reasoning skills, it may be difficult to isolate the effects of literacy at an individual level because of the ubiquitousness of mediated effects. In contrast to the global reasoning skills emphasized in the cross-cultural investigations, we chose to focus on domains that would seem more likely to reflect the direct effects of differences in print exposure: vocabulary, cultural knowledge, spelling, and verbal fluency.

Our rationale for choosing these types of variables was influenced by the outcomes of Scribner and Cole's (1981) groundbreaking investigation of literacy without schooling in the Vai of West Africa. In the first part of their investigation, they concentrated on looking for effects of literacy on tasks that tapped developmental change in general cognitive processes. These included conceptual abstraction tasks, taxonomic classification, memory and memory clustering, syllogistic logic, and language objectivity. Specific effects of literacy on these tasks were spotty. Thus, "Hypotheses derived from general abstract characterizations of literacy ... lost their power of attraction" (Scribner \& Cole, 1981, p. 158), and Scribner and Cole shifted their strategy toward another hypothesis they had entertained, that "cognitive consequences of literacy, should they be found, would be closely tied to the functional uses of literacy among the Vai" (p. 159).

The tasks in the second part of Scribner and Cole's (1981) investigation-rebus reading, integrating auditory information, word pronunciation, and communication gameswere more closely tied to aspects of Vai literacy, and it was easier to demonstrate specific effects of literacy on these tasks. In our research program on the cognitive con- sequences of differences in print exposure, we are inverting the investigative chronology of Scribner and Cole (1981) by starting with tasks that are more closely linked to literacy skills. Contingent on positive outcomes in these domains, we will then begin to examine more general cognitive processes.

Thus, following this research logic, we established our methodology (see Stanovich \& West, 1989) by examining criterion variables-orthographic knowledge and spelling - that should clearly be linked to individual differences in print exposure. In the present investigation, we expanded the set of criterion variables to encompass broader domains such as vocabulary, cultural knowledge, and verbal fluency. Although specific effects of print exposure on a variable such as vocabulary knowledge would represent a more general effect of literacy activity than would effects on orthographic knowledge, there is still some reason to expect a positive outcome here, because research has shown that measures of lexical density differ for speech and text, the latter containing vastly more infrequent and complex words (Corson, 1985; Hayes, 1988; Hayes \& Ahrens, 1988) than the former. Positive results with such variables will encourage us to probe the connections between print exposure and more generalized cognitive skills of the type that have been discussed in the theorizing of cognitive anthropologists (e.g., syllogistic reasoning, decontextualized thinking; see Goody, $1977,1987)$. That is, we do not consider Scribner and Cole's (1981) research, influential and provocative though it was, to be the final word on the issue of the cognitive consequences of literacy. The research strategy and methods that we shall outline below will provide a converging method for studying the consequences of engaging in reading activities by utilizing the normal range of variation in a literate society rather than by employing a comparison of literates with illiterates in a society with less than uniform literacy.

\section{Methodological Problems in Assessing the Direct Cognitive Consequences of Literacy}

Cultural anthropologists (e.g., Luria, 1976), and to a lesser extent cognitive psychologists (e.g., Morais, Bertelson, Cary, \& Alegria, 1986), have sometimes attempted to study literate and nonliterate individuals within cultures in which there are still many illiterates. Such an extreme groups comparison gives a discrete or dichotomous look at the effects of the absence versus presence of literacy and is clearly very diagnostic. However, the discrete comparison of literates with illiterates is beyond the logistical capabilities of most investigators, including the present authors. Instead, our methodology exploits the fact that even within a generally literate culture there are tremendous variations in degrees of exposure to print (Anderson et al., 1988; Guthrie \& Greaney, 1991; Guthrie \& Seifert, 1983). Even among a group of individuals who have the same levels of assessed reading-comprehension ability, there are surprisingly large differences in degree of engagement in print-related activities (Stanovich \& 
West, 1989). It is thus possible to study the correlates of this natural variation in print exposure within a generally literate society. Research comparing literates with illiterates is the exclusive design of choice only if it is believed that the effects of print exposure are completely discontinuous-that is, there are no cognitive consequences associated with individual differences in print exposure within a literate society.

In our methodology, we attempt to correlate differential engagement in reading activities with various cognitive outcomes that have been associated with the acquisition of literacy. However, such an experimental logic, if not supplemented with additional methodological controls, will yield data that is subject to an inordinately large number of alternative explanations. Again, historical and cross-cultural studies provide some context for understanding the methodological difficulties in studying the nonmediated effects of differential print exposure within literate societies. Consider the recent changes in how historians and sociologists view certain cultural correlates of literacy (Graff, 1986, 1987; Kaestle, 1991; Wagner, 1987). There was, in earlier writings, a tendency to attribute every positive outcome that was historically correlated with the rise of literacy-economic development, for example-to the effects of literacy itself. However, it is now recognized that the potential for spurious correlation in the domain of literacy is quite high. Simply put, high levels of societal literacy are correlated with too many other good things. Thus, it is now seen as a mistake to automatically attribute everything that is historically correlated with the rise of literacy to the effects of literacy itself. For example, the link between economic development and national levels of literacy has turned out to be much more complex than originally thought. Literacy levels are as much a consequence of economic development as they are its cause (Fuller, Edwards, \& Gorman, 1987; Kaestle, 1991; Wagner, 1987).

The inferential problems in assessing the consequences of print exposure at the level of the individual reader are analogous to the problem of comparing the effects of different levels of literacy across societies or historical periods. Levels of print exposure are correlated with too many other cognitive and behavioral characteristics. Avid readers tend to be different from nonreaders on a wide variety of cognitive skills, behavioral habits, and background variables. Attributing any particular outcome to print exposure alone is extremely difficult.

We have used a regression logic to deal with this problem. In our analyses, we first regress out general measures of cognitive ability before examining the relationship between print exposure and criterion variables. This procedure of reducing possible spurious relationships by first partialing relevant ability measures was used in our earlier investigations of subword processes in reading. For example, in previous work, we have demonstrated that, independent of decoding ability, variation in print exposure among adults predicts variation in specific types of orthographic knowledge (Stanovich \& West, 1989). Similarly, in a study of children's performance (Cunningham \& Stanovich, 1990), we found that after partialing IQ, memory ability, and phonological processing abilities, print exposure accounted for significant variance in orthographic knowledge and word recognition. Anderson et al. (1988) employed this regression logic in their activity-diary study. After partialing out overall levels of reading ability (see also Cunningham \& Stanovich, 1991; Taylor, Frye, \& Maruyama, 1990), they linked differences in time spent reading to vocabulary and reading speed.

The logic of our analytic strategy is quite conservative, because in certain analyses, we have actually partialed out variance in abilities that are likely to be developed by print exposure itself (Stanovich, 1986). However, the explanatory ambiguities surrounding a variable such as print exposure have led us to continue to structure the analyses in a "worst case" manner as far as print exposure is concerned. When the predictive power of print exposure survives such biased analyses, we do begin to feel justified in advancing at least a tentative causal inference.

In the present investigation, we examined whether a variety of verbal skills could be linked to variation in the amount of print exposure after the effects of general ability had been partialed. Criterion variables in the investigation were two different measures of vocabulary, a measure of cultural knowledge, two measures of spelling ability, and a verbal fluency task. The tasks that we employed to partial general ability were Raven's (1962) Advanced Progressive Matrices, a figural analogies test, and a reading-comprehension test. The present study was also part of a continuing attempt to develop and validate new techniques for assessing relative individual differences in print exposure that may have some unique methodological advantages.

\section{Assessing Print Exposure}

There are numerous difficulties involved in assessing individual differences in exposure to print. Activity-diary methods, in which daily activity records are filled out by subjects (see Anderson et al., 1988; Greaney, 1980; Greaney \& Hegarty, 1987; Rice, 1986; Taylor et al., 1990), result in estimates of the absolute amount of time spent on literacy activities. Other techniques are available if one wants only an index of relative differences in exposure to print. For example, a variety of questionnaire and interview techniques have been used to assess relative differences in print exposure (e.g., Estes, 1971; Guthrie, 1981; Guthrie \& Greaney, 1991; Guthrie \& Seifert, 1983; Lewis \& Teale, 1980; Sharon, 1973-1974; Walberg \& Tsai, 1984), but many of these are encumbered with social-desirability confounds: responses are distorted because of the tendency to report socially desirable behaviors (Furnham, 1986; Paulhus, 1984)-in this case, the tendency to report more reading than actually takes place (Ennis, 1965; Sharon, 1973-1974; Zill \& Winglee, 1990). This problem is particularly acute in cases 
such as the present one, in which relatively educated people are asked questions about a socially valued activity such as reading.

In the present study, we used a variety of questionnaire methods to assess print exposure, with the methods varying in their susceptibility to social-desirability confounds. More importantly, however, we report further data on two recognition measures of print exposure-the Author Recognition Test (ART) and the Magazine Recognition Test (MRT) - that proved to be robust predictors in earlier studies (e.g., Stanovich \& West, 1989; West \& Stanovich, 1991). Both employ a signal-detection logic, whereby subjects must recognize actual target items (real authors and real magazines) when they are embedded among foils (names that are not authors or magazine titles, respectively). There are several advantages to this checklist-withfoils method. First, it is immune to the social-desirability effects that so contaminate responses to subjective self estimates of socially valued activities such as reading. Guessing is not an advantageous strategy because it is easily detected and corrected for by an examination of the number of foils checked. Furthermore, the cognitive demands of the task are quite low. Using these recognition measures in conjunction with a variety of questionnaire methods provides an opportunity to assess whether different measures of print exposure display convergent validity.

\section{METHOD}

\section{Subjects}

The subjects were 300 undergraduate students $(114$ males and 186 females) recruited through two introductory psychology subject pools. Two hundred twenty-one subjects were recruited from a large, selective (according to Peterson's Guides, 1990) state university; 79 of the subjects were recruited from a less selective (according to Peterson's Guides, 1990), medium-sized state university. Although the sample from the large, selective state university outperformed the sample from the less selective state university on most measures, all of the relationships described below were replicated in each of the samples considered separately. Therefore, the analyses reported here utilize the combined sample.

\section{Cognitive Tasks}

Reading comprehension. The subjects completed the comprehension subtest of the Nelson-Denny Reading Test (Form F; Brown. Bennett, \& Hanna, 1981). To cut the administration time from $20 \mathrm{~min}$ to $16 \mathrm{~min}$, the long initial passage of Form F (lengthened in order to allow assessment of reading rate) was omitted, along with its 8 questions. The subjects thus completed seven of the eight passages and answered the 28 questions associated with those seven passages. The split-half reliability of this slightly shortened version of the test (.72, Spearman-Brown corrected) was not appreciably different from the alternate-form reliability of .77 reported in the test manual (Brown et al., 1981). Raw scores were used in the analyses that follow.

Raven's matrices. The subjects completed 18 problems from Raven's Advanced Progressive Matrices (Raven, 1962, Set II), a task tapping general problem-solving skills and commonly viewed as a good measure of analytic intelligence (Carpenter, Just, \& Shell, 1990). The subject is required to solve problems presented in abstract figures and designs. The test consists of a booklet containing pictures of a pattern with a section missing and eight options to choose from in replacing the missing portion of the pattern. The subjects completed one practice problem along with the experimenter as the experimenter explained the test. The subjects then were given $15 \mathrm{~min}$ to complete the 18 items on the test. The 18 items chosen were numbers $12,14,15,16,17,18,19,20,21,22,23,24$, $25,26,27,28,29$, and 30 . By eliminating 12 of the easiest problems, in which performance in a college sample is near ceiling (Carpenter et al., 1990; Raven, Court, \& Raven, 1977), and 6 of the most difficult problems, in which performance is nearly floored (Carpenter et al., 1990; Raven et al., 1977), we tried to achieve a cut-time version of the Advanced Progressive Matrices that would still have adequate reliability and discriminating power. A previous investigation used a 16-item version of the Standard Progressive Matrices for cut-time administration and achieved reliabilities over .75 in samples of children (Cahan \& Cohen, 1989). The split-half reliability of our 18-item measure $(.79$, SpearmanBrown corrected) was similar. Raw scores were used in the analyses that follow.

Figural analogies. The subjects completed 15 figural analogy problems taken from Sternberg (1988, pp. 136-138). In these problems, each subject views three terms of a visual analogy. There is a relationship between the first 2 figures. From four alternatives for the fourth term, the subject must choose the one that relates to the third in the same manner as the second does to the first. The subjects completed one practice problem along with the experimenter as the experimenter explained the test. The subjects then were given $4 \frac{1 / 2}{m i n}$ to complete the 15 items on the test. The split-half reliability of the measure (Spearman-Brown corrected) was .78. Raw scores were used in the analyses that follow.

Nelson-Denny vocabulary. The subjects completed 20 items chosen from Form $F$ of the vocabulary subtest of the Nelson-Denny Reading Test (Brown et al., 1981). To complete the test, the subject read an incomplete sentence containing the key vocabulary word and then chose from among five written alternatives the word or short phrase that correctly completed the sentence (example: Militant persons are usually: a. hopeless, b. fearful, c. strengthened, d. matter-of-fact, e. aggressive). The items chosen for group administration were numbers $27,29,35,36,39,41,43,45,46$, $47,48,52,54,56,57,58,60,66,68$, and 69 . The subjects were given $5 \mathrm{~min}$ to complete the 20 items on the test. The split-half reliability of the measure (Spearman-Brown corrected) was .82. Raw scores were used in the analyses that follow.

Peabody Picture Vocabulary Test. The subjects were group administered 20 items chosen from Form L of the Peabody Picture Vocabulary Test (PPVT; Dunn \& Dunn, 1981). Each subject had a booklet of picture alternatives. The subjects looked at four picture alternatives while the experimenter said a word out loud. Their task was to choose one of the four pictures that best described the meaning of the word and to write down the number of the picture on a separate score sheet. Thus, the PPVT is an oral receptive vocabulary measure. The 20 PPVT items ranged in number on Form $L$ from 150 to 174 . The split-half reliability of the measure (Spearman-Brown corrected) was .79. Raw scores were used in the analyses that follow.

Verbal fluency task. The subjects were administered four trials of a verbal fluency task (see Sincoff \& Sternberg, 1987) in which they had to write down as many words in a given category as they could within $45 \mathrm{sec}$. The categories, in the order administered, consisted of words that begin with the letter " $k$," words that begin with the letter " $a$," words that rhyme with "cash," and words that rhyme with "jack." Accurate spelling was not required on the task. The subject's score was simply the total number of items generated across the four categories. The split-half reliability of the measure (Spearman-Brown corrected) was .72 .

History and literature knowledge. The subjects were group administered a selection of 20 items from the National Assessment of Educational Progress test of high school history and literature knowledge (Ravitch \& Finn, 1987). Ten items were selected from 
the history section (e.g. " "Who was the leader of the Soviet Union when the United States entered the Second World War?" a. Yuri Gagarin, b. Marshal Tito, c. Joseph Stalin, d. Nikita Khrushchev) and 10 from the literature section (e.g., " Which mythical Greek hero demonstrated his bravery and cunning during his long journey homeward after fighting in the Trojan War?" a. Theseus, b. Achilles, c. Odysseus, d. Telemachus). All items were in multiple-choice format. There was no time limit on the task. The split-half reliability of the measure (odd-even, mixing history and literature items, and Spearman-Brown corrected) was .75. The 10 history items displayed a correlation of .50 with the 10 literature items. The raw scores on the entire 20-item test were used in the analyses that follow.

Spelling production. Twenty words were employed in the spelling-production task (necessity, opportunity, conscience, courteous, possession, exaggerate, privilege, effeminate, resilient, aggravate, defensible, sergeant, subpoena, inexhaustible, annihilate, repetition, definitely, recommend, plagiarism, regrettable), 9 of which were stimuli used in Spelling Level 2 of the Wide Range Achievement Test (Jastak \& Wilkinson, 1984) and 11 of which were stimuli from the Experimental Spelling Test developed by Fischer, Shankweiler, and Liberman (1985). The experimenter pronounced each word, used each word in a sentence (e.g., "Food is a necessity of life'), and pronounced the word again. The subjects were asked to spell the word as best they could on a score sheet. Scores on the measure were simply the number of words spelled correctly.

Spelling recognition. Fifteen words (incessant, conscientious, countenance, souvenir, combustible, proficiency, embarrassment, fallacy, surreptitiously, occasionally, picnicking, disappointment, soliloquy, inoculate, exacerbate) taken from the Peabody Individual Achievement Test (Dunn \& Markwardt, 1970) were employed as stimuli. The experimenter pronounced each word, used each word in a sentence, and pronounced the word again. For each target word (e.g., incessant), the subject viewed four alternatives, three of which were incorrect (e.g., insescent, inncessant, incessant, insessant). The subjects simply had to indicate their choice on a score sheet. Scores on the measure were simply the number of correct choices.

Although the processing requirements of the spelling-production and spelling-recognition measures varied greatly, performance on the two tasks was highly correlated $(r=.76)$. Because of the high correlation between the two spelling measures, and because they displayed almost identical correlations with other variables in the study, a composite spelling index was calculated. For each subject, the number of correct spelling-production responses and the number of correct spelling-recognition responses were both converted to $z$ scores. These two $z$ scores were then averaged to form a composite index of overall spelling performance.

\section{Print Exposure Measures}

Author Recognition Test. The ART was explicitly designed to circumvent the problem of questionnaire contamination by tendencies toward socially desirable responses (see Stanovich \& West, 1989). The ART is a checklist in which subjects indicate that they are familiar with the name of a particular popular author/writer by putting a check mark next to the name. There are $\mathbf{4 0}$ names of writers/authors on the ART. Subjects are prevented from simply checking all of the names by the presence of 40 foils-names of people who are not popular writers/authors.

The version of the ART employed in the present investigation was similar to that employed in an initial investigation in which the measure was introduced (see Stanovich \& West, 1989), except that the instrument was improved on the basis of the results of the earlier investigation. Specifically, items that demonstrated poor psychometric properties in the previous investigation (c.g., those demonstrating ceiling or floor effects) were removed and replaced by more promising candidates. The $\mathbf{4 0}$ authors appearing on the ART are listed in Appendix A, along with the percentage of times that the item was correctly checked. The list is dominated by "popular" authors as opposed to "highbrow" writers who would be known by only the most academically inclined readers. Many of the book authors regularly appear on best-seller lists, and most have sold hundreds of thousands, if not millions, of volumes (see Publishers Weekly, March 9. 1990. pp. 17-37. and Stanovich \& West. 1989). Indeed, some authors were on the best-seller lists at the time this study was conducted. For example. 13 of the writers on the ART authored a mass-market paperback that had over I million copies in print in 1989 (Publishers Weekly, March 9, 1990, pp. 17-37). These 13 authors were responsible for 19 different books that had over 44 million copies in print. These are figures for the year 1989 only. Cumulative lists from previous years would take in many more of the authors on the ART. For example, 18 of the 25 top fiction best-sellers of the 1980 s were authored by individuals on the ART (Publishers Weekly, January 5, 1990, pp. 24-26). Clearly, these circulation figures demonstrate that the authors on the ART produce popular works for the general public.

Although no statistical sampling of authors was carried out, an attempt was made to mix writers from a wide variety of genres. Thus, most major categories of nonfiction (e.g., science, politics/ current events, humor, religion, history, biography, business/finance. travel) and fiction (e.g., mystery/detective, romance/Gothic, spy/ intrigue, occult/supernatural, historical novels, Westerns, short stories, science fiction) were represented. In constructing the list so that the ART would be a proxy measure of out-of-school print exposure, authors were selected who were most likely to be encountered outside of the classroom. Thus, an attempt was made to avoid authors who are regularly studied in the school curriculum. None of the authors appears in Ravitch and Finn's (1987) survey of the high school literature curriculum. Perhaps only James Baldwin comes close to being a "curriculum author." In short, the ART was intentionally biased toward out-of-school reading, because it was intended as an indirect measure of free-reading volume.

The 40 foils in the ART were names taken from the editorial board of Volume 22 (1987) of Reading Research Quarterly. Full names were used in all cases, except those in which the individual habitually used initials (e.g. S. E. Hinton). On the response sheet that the subjects completed, this measure was labeled the Author Recog. nition Questionnaire and was referred to in this manner by the experimenter. The instructions to the subjects read as follows:

Below you will see a list of 80 names. Some of the people in the list are popular writers (of books, magazine articles, and/or newspaper columns) and some are not. You are to read the names and put a check mark next to the names of those individuals who you know to be writers. Do not guess, but only check those who you know to be writers. Remember, some of the names are people who are not popular writers, so guessing can easily be detected.

These instructions resulted in only a few foils being checked. The mean number of foils checked per subject was 0.8 . The mode was zero $(N=184)$, and 272 of the 300 subjects checked 2 foils or less.

Scoring on the task was determined by taking the proportion of correct items checked and subtracting the proportion of foils checked. This is the discrimination index from the two-high threshold model of recognition performance (Snodgrass \& Corwin, 1988). Other corrections for guessing and differential criterion effects (see Snodgrass \& Corwin, 1988) produced virtually identical correlational results. The reliability of the number of correct items checked was .89 (Cronbach's alpha). There was no time limit for completing the task, but it took most subjects less than $5 \mathrm{~min}$.

Magarine Recognition Test. The logic and structure of the MRT was analogous to that of the ART, but it was designed to tap a possibly different type of out-of-school reading. Although the ART contains writers whose work sometimes appears in magazines and newspapers, it is nevertheless heavily biased toward authors of books. The MRT was thus designed to balance the ART by sampling magazine-reading exclusively.

The 80 items on the MRT consisted of the names of 40 magazines and $\mathbf{4 0}$ foils. The $\mathbf{4 0}$ magazines appearing on the MRT (see Appendix B) represent a slight alteration of the titles used in an 
initial investigation, in which the measure was introduced (see Stanovich \& West, 1989). The sampling of titles was deliberately biased toward popular publications. "Highbrow" or low-circulation "small press" publications that would be known by only the most academically inclined readers were avoided. The list includes some of the most well-known publications in the United States (e.g. Newsweek, Sports llustrated). Statistics taken from The Standard Periodical Directory (Manning, 1988) indicated that 14 of the 40 publications on the MRT had circulations over 1 million and 32 had circulations of over 500,000 . The mean circulation of the items on the MRT was $1,314,755$, and the median circulation was 782,650 . The percentage recognition of the MRT items, listed in the first column of Appendix B, displayed a correlation of .64 with the natural logarithm of the magazine's circulation.

Although no statistical sampling of magazines was carried out, an attempt was made to attain a mix of genres. Thus, most major categories of publications (sports, current events, music, gossip, science, politics, humor, finance, homemaking, outdoors, fashion, technology, cars) were represented. The $\mathbf{4 0}$ foil names (see Appendix C of Stanovich \& West, 1989) did not appear in the 60,000 listings in The Standard Periodical Directory (Manning, 1988). The 80 names were listed in alphabetical order, mixing targets and foils.

On the response sheet that the subjects completed, this measure was labeled the Magazine Recognition Questionnaire and was referred to in this manner by the experimenter. The instructions for the MRT were as follows:

Below you will see a list of $\mathbf{8 0}$ titles. Some of them are the names of actual magazines and some are not. You are to read the names and put a check mark next to the names of those that you know to be magazines. Do not guess, but only check those that you know to be actual magazines. Remember, some of the tites are not those of popular magazines, so guessing can easily be detected.

These instructions resulted in only a few foils being checked. The mean number of foils checked per subject was 1.8 . The mode was zero $(N=97)$, and 222 of the 300 subjects checked 2 foils or less. Scoring on the task was determined by taking the proportion of correct items checked and subtracting the proportion of foils checked. As with the ART, alternative corrections for guessing and differential criterion effects produced virtually identical results. The reliability of the number of correct items checked was .87 (Cronbach's alpha). There was no time limit for completing the task, but it took most subjects 5 min.

For some of the analyses reported below, we employed a composite index of performance on the ART and the MRT, because the two measures were highly correlated (.64) and displayed similar relationships with other variables in the study. For each subject, scores on both the ART and MRT were converted to $z$ scores. These two $z$ scores were then averaged to form a composite index of print exposure as measured by these checklist tasks (ARTMRTZ).

Activity-preference questionnaire. The instructions for the activity-preference questionnaire were as follows:

Below you will be given a choice between engaging in one of two activities. Please put a check mark next to the one that you prefer. Please mark only one. That is, even if you like both activities, please mark only the one you like best. Similarly, even if you dislike both activities, mark the one that you would prefer to do. For each item, please mark only one choice.

There followed 12 forced choices for the subject, in the format, "I would rather: a. listen to music of my choice, b. watch a television program of my choice." Six of the questions concerned reading (the other 6 served as fillers to disguise the focus on reading). In these 6 items, "read a book of my choice" was pitted against "watch a television program of my choice," "play an outdoor sport of my choice," "listen to music of my choice," "talk with friends of my choice," "attend a movie of my choice," and "spend time on my hobbies." The subject's score on the task was simply the number of times that reading was chosen over 1 of these 6 activities. Scores thus ranged from 0 to 6 .

Reading- and medin-habits questionnaire. The subjects were administered a reading- and media-habits questionnaire that contained questions about reading habits, television habits, study habits, and high school history. Only the reading section of the questionnaire will be considered here. Four questions were answered by choosing one of several multiple-choice alternatives. The questions probed whether the student read for pleasure, read books in addition to those for college courses, subscribed to or bought magazines, and read newspapers. The responses on these four questions were scored so that higher scores reflected more reading. Two openended items asked the subjects to name all of the magazines that they subscribed to or bought regularly and to name two or three of their favorite authors/writers.

Appendix $C$ presents a correlation matrix in which the six reading items on the questionnaire were correlated with the other measures of print exposure (the ART, MRT, and the activity-preference measure) and one outcome variable (PPVT). Two of the multiplechoice items (reading for pleasure and reading books in addition to those for college courses) correlated with both the PPVT and with the other measures of print exposure. The other two multiplechoice items displayed distinctly lower (often nonsignificant) correlations with the other print exposure measures and the PPVT. A reading-questionnaire composite was thus formed by simply combining performance on the two multiple-choice items that concerned reading for pleasure and reading books in addition to those for college courses (the correlation between the two items was .49). Each subject's responses to these items were converted to $z$ scores. The two $z$ scores were then averaged to form a composite index of print exposure as measured in these two questionnaire items.

The data in Appendix $C$ indicate that although the open-ended item that asked the subjects to name all of the magazines that they subscribed to or bought regularly did correlate with the multiplechoice item on magazines, it failed to correlate with any of the other variables. This item was dropped from further consideration. Consistent with the results of a previous investigation (Stanovich \& West, 1989), the open-ended question that asked subjects to name their two or three favorite authors/writers was very diagnostic, even though it was scored in a very crude manner. That is, every name volunteered was accepted as an adequate response and treated equally. The question was simply scored $3,2,1,0$, according to whether the subject wrote down three names $(N=132)$, two names $(N=94)$, one name $(N=42)$, or left the question blank $(N=32)$. Scores on this item were treated as a separate variable. It will be referred to as the favorite-authors item.

\section{Procedure}

Subjects completed all of the tasks in one 2-h session. The order of tasks was the same for all subjects: spelling production, NelsonDenny reading comprehension, PPVT, spelling recognition, readingand media-habits questionnaire, activity-preference questionnaire, MRT, ART, figural analogies, Nelson-Denny vocabulary, Raven matrices, verbal fluency, and history/literature knowledge.

\section{RESULTS}

Table 1 presents a correlation matrix that displays the relationships among all of the major variables in the study. All of the measures of print exposure were significantly correlated, although with the exception of the ART and MRT (.64) and the reading questionnaire and activitypreference measure $(.60)$, the correlations were quite modest. This was probably due to the briefness, and hence low reliability, of some of the measures. The ART and 
Table 1

Intercorrelations Among the Primary Variables

\begin{tabular}{|c|c|c|c|c|c|c|c|c|c|c|c|c|c|}
\hline Variable & 1 & 2 & 3 & 4 & 5 & 6 & 7 & 8 & 9 & 10 & 11 & 12 & 13 \\
\hline 1 ART & & & & & & & & & & & & & \\
\hline 2 MRT & 64 & & & & & & & & & & & & \\
\hline 3 ARTMRTZ & .91 & .91 & & & & & & & & & & & \\
\hline 4 Favonie-author question & .44 & .38 & .45 & & & & & & & & & & \\
\hline 5 Activity preference-reading & .42 & .21 & .34 & .31 & & & & & & & & & \\
\hline 6 Reading questionnaire & .36 & .22 & .32 & .30 & 60 & & & & & & & & \\
\hline 7 Raven matrices & .30 & .39 & .38 & .25 & .17 & .17 & & & & & & & \\
\hline 8 Figural analogies & .24 & .32 & .30 & .15 & .09 & .12 & 47 & & & & & & \\
\hline 9 Nelson-Denny comprehension & .54 & .48 & .56 & .36 & .35 & .30 & .42 & .33 & & & & & \\
\hline 10 Nelson-Denny vocabulary & .60 & .56 & .64 & .44 & .34 & .23 & .48 & 32 & 65 & & & & \\
\hline 11 PPVT & .64 & 57 & .67 & .35 & .31 & 23 & .39 & .28 & .50 & $.7 !$ & & & \\
\hline 12 Verbal fluency & .40 & .30 & .38 & .21 & .17 & 14 & .21 & .21 & 30 & .37 & .38 & & \\
\hline 13 History and literature (NAEP) & .59 & .54 & .62 & .45 & 32 & .28 & .34 & .28 & 59 & .63 & 61 & .24 & \\
\hline 14 Spelling composite & .51 & .37 & .49 & .36 & .28 & .20 & .35 & .24 & .57 & .59 & .53 & .35 & .48 \\
\hline
\end{tabular}

Note-Correlations greater than .12 in absolute value are significant at the .05 level. Correlations greater than .15 in absolute value are significant at the .01 level,

MRT were the print exposure measures most highly correlated with the other variables in the study. These two tasks displayed very similar correlations with other variables in the study, although there was a consistent trend for the ART to correlate more highly with the verbal tasks and with other measures of print exposure.

The correlations in Table 1 indicate that all of the measures of print exposure relate to measures of verbal abilities. However, the zero-order correlations do not address the issue of the specificity of the relationship between print exposure and the other variables. A series of hierarchical regression analyses was conducted to examine whether the measures of print exposure could account for variance in verbal abilities once general ability was partialed out. A weak test of this typothesis (Table 2) will be followed by the presentation of a stronger test (Table 3).
The first set of analyses (presented in Table 2) partialed general ability, as measured by the two nonverbal tasks, before entering the print exposure measures. The top half of Table 2 contains the cumulative $r s$ resulting from forcing first figural analogies performance and then Raven matrices performance into the equation. Below the line are the cumulative rs that resulted when each of the five measures of prist exposure was entered at the third step. The bottom half of Table 2 presents the $r^{2}$ change values at each step of the anslysis and indicates whether the $r^{2}$ change values were significant at that step.

The results indicated that after performance on the figural analogies and Raven tasks was partialed, four of the five print exposure measures (ART, MRT, favoriteauthor question, and activity-preference measure) accounted for additional variance in every criterion vari-

Table 2

Unique Print Exposure Variance After Nonverbal Abilities Are Partialed Out

\begin{tabular}{|c|c|c|c|c|c|c|c|}
\hline \multirow[b]{2}{*}{ Step } & \multirow[b]{2}{*}{ Variable } & \multicolumn{6}{|c|}{ Dependent Variables } \\
\hline & & 1 & 2 & 3 & 4 & $s$ & 6 \\
\hline \multicolumn{8}{|c|}{ Cumulative $r$} \\
\hline $\begin{array}{ll}1 & F \\
2 & F\end{array}$ & $\begin{array}{l}\text { Figural analogies } \\
\text { Raven matrices }\end{array}$ & $\begin{array}{l}.316 \\
.488\end{array}$ & $\begin{array}{l}.278 \\
.405\end{array}$ & $\begin{array}{l}.280 \\
.369\end{array}$ & $\begin{array}{l}.332 \\
.446\end{array}$ & $\begin{array}{l}.238 \\
.362\end{array}$ & $\begin{array}{l}.205 \\
.243\end{array}$ \\
\hline $\begin{array}{ll}3 & A \\
3 & 1 \\
3 & 5 \\
3 & A \\
3 & 5\end{array}$ & $\begin{array}{l}\text { ART } \\
\text { MRT } \\
\text { Favorite author } \\
\text { Activity preference } \\
\text { Reading questionsare }\end{array}$ & $\begin{array}{l}.675 \\
.628 \\
.591 \\
.555 \\
.511\end{array}$ & $\begin{array}{l}.677 \\
.599 \\
.480 \\
.474 \\
.434\end{array}$ & $\begin{array}{l}.620 \\
.564 \\
.524 \\
.451 \\
.428\end{array}$ & $\begin{array}{l}.609 \\
.548 \\
.518 \\
.526 \\
.501\end{array}$ & $\begin{array}{l}.549 \\
.438 \\
.455 \\
.427 \\
.389\end{array}$ & $\begin{array}{l}.418 \\
.325 \\
.289 \\
.279 \\
.263\end{array}$ \\
\hline \multicolumn{8}{|c|}{$r^{2}$ Change } \\
\hline 11 & $\begin{array}{l}\text { Figural analogies } \\
\text { Raven matrices }\end{array}$ & $\begin{array}{l}.100 \dagger \\
.138 \dagger\end{array}$ & $\begin{array}{l}.077 \dagger \\
.087 \dagger\end{array}$ & $\begin{array}{l}.079 \dagger \\
.057 \dagger\end{array}$ & $\begin{array}{l}.110 \dagger \\
.089 \dagger\end{array}$ & $\begin{array}{l}.057 \dagger \\
.074 t\end{array}$ & $\begin{array}{l}.042 \dagger \\
.017^{*}\end{array}$ \\
\hline $\begin{array}{ll}3 & 1 \\
3 & 1 \\
3 & 1 \\
3 & 1 \\
3 & 1\end{array}$ & $\begin{array}{l}\text { ART } \\
\text { MRT } \\
\text { Favorite author } \\
\text { Activity preference } \\
\text { Reading questionnaire }\end{array}$ & $\begin{array}{l}.218+ \\
.156 \dagger \\
.111 \dagger \\
.070 \dagger \\
.023^{*}\end{array}$ & $\begin{array}{l}.294 t \\
.194 t \\
.066 t \\
.061 t \\
.025 *\end{array}$ & $\begin{array}{l}.248 \dagger \\
.182 \dagger \\
.139 t \\
.068 \dagger \\
.048 \dagger\end{array}$ & $\begin{array}{l}.171 \dagger \\
.102 \dagger \\
.070 \dagger \\
.078 \dagger \\
.052 \dagger\end{array}$ & $\begin{array}{l}.170 t \\
.061 t \\
.076 t \\
.051 t \\
.020\end{array}$ & $\begin{array}{l}.116 \dagger \\
.047 \dagger \\
.024^{*} \\
.019^{*} \\
.010\end{array}$ \\
\hline
\end{tabular}

Note-Dependent variables: 1 = Nelson-Denny vocabulary, 2 = PPVT, 3 = History and literature (NAEP), $4=$ Nelson-Denny comprehension, $5=$ Spelling composite, and $6=$ Verbal fluency. $\quad * p<.05 \quad+p<.001$. 
Table 3

Unique Print Exposure Variance After Nonverbal Abilities and Reading-Comprehension Ability Are Partialed Out

\begin{tabular}{|c|c|c|c|c|c|c|}
\hline \multirow[b]{2}{*}{ Step } & \multirow[b]{2}{*}{ Variable } & \multicolumn{5}{|c|}{ Dependent Variables } \\
\hline & & 1 & 2 & 3 & 4 & 5 \\
\hline \multicolumn{7}{|c|}{ Cumulative $r$} \\
\hline $\begin{array}{l}1 \\
2 \\
3\end{array}$ & $\begin{array}{l}\text { Figural analogies } \\
\text { Raven matrices } \\
\text { Nelson-Denny comprehension }\end{array}$ & $\begin{array}{l}.316 \\
.488 \\
.684\end{array}$ & $\begin{array}{l}.278 \\
.405 \\
.541\end{array}$ & $\begin{array}{l}.280 \\
.369 \\
.599\end{array}$ & $\begin{array}{l}.238 \\
.362 \\
.582\end{array}$ & $\begin{array}{l}.205 \\
.243 \\
.323\end{array}$ \\
\hline $\begin{array}{l}4 \\
4 \\
4 \\
4 \\
4\end{array}$ & $\begin{array}{l}\text { ART } \\
\text { MRT } \\
\text { Favorite author } \\
\text { Activity preference } \\
\text { Reading questionnaire }\end{array}$ & $\begin{array}{l}.738 \\
.725 \\
.713 \\
.695 \\
.685\end{array}$ & $\begin{array}{l}.688 \\
.636 \\
.564 \\
.559 \\
.545\end{array}$ & $\begin{array}{l}.677 \\
.660 \\
.646 \\
.610 \\
.607\end{array}$ & $\begin{array}{l}.625 \\
.589 \\
.601 \\
.589 \\
.583\end{array}$ & $\begin{array}{l}.423 \\
.356 \\
.337 \\
.331 \\
.326\end{array}$ \\
\hline \multicolumn{7}{|c|}{$r^{2}$ Change } \\
\hline $\begin{array}{l}1 \\
2 \\
3\end{array}$ & $\begin{array}{l}\text { Figural analogies } \\
\text { Raven matrices } \\
\text { Nelson-Denny comprehension }\end{array}$ & $\begin{array}{l}.100 \dagger \\
.138 \dagger \\
.230 \dagger\end{array}$ & $\begin{array}{l}.077 \dagger \\
.087 \dagger \\
.129 \dagger\end{array}$ & $\begin{array}{l}.079 \dagger \\
.057 \dagger \\
.222 \dagger\end{array}$ & $\begin{array}{l}.057 \dagger \\
.074 \dagger \\
.208 \dagger\end{array}$ & $\begin{array}{l}.042 \dagger \\
.017^{*} \\
.045 \dagger\end{array}$ \\
\hline $\begin{array}{l}4 \\
4 \\
4 \\
4 \\
4\end{array}$ & $\begin{array}{l}\text { ART } \\
\text { MRT } \\
\text { Favorite author } \\
\text { Activity preference } \\
\text { Reading questionnaire }\end{array}$ & $\begin{array}{l}.076 \dagger \\
.058 \dagger \\
.040 \dagger \\
.015^{*} \\
.001\end{array}$ & $\begin{array}{l}.180 \dagger \\
.112 \dagger \\
.025^{*} \\
.020^{*} \\
.005\end{array}$ & $\begin{array}{l}.100 \dagger \\
.077 \dagger \\
.060 \dagger \\
.015^{*} \\
.011^{*}\end{array}$ & $\begin{array}{l}.052 \dagger \\
.008 \\
.022^{\star} \\
.008 \\
.001\end{array}$ & $\begin{array}{l}.075 \dagger \\
.023^{*} \\
.010 \\
.006 \\
.003\end{array}$ \\
\hline
\end{tabular}

Note-Dependent variables: $1=$ Nelson-Denny vocabulary, $2=$ PPVT, $3=$ History and literature (NAEP), $4=$ Spelling composite, and $5=$ Verbal fluency. $\quad{ }^{*} p<.05$ $+p<.001$.

able in the study. Print exposure, as indexed by the two book items on the reading questionnaire, accounted for additional variance in five of the six criterion variables. In many cases (particularly those involving the ART and MRT), the unique variance explained was sizable. These analyses indicate that a variety of different measures of print exposure can explain variance in verbal tasks not accounted for by general ability.

The next set of analyses provides a much more stringent test of the ability of the print exposure indicators to account for unique variance. The analyses in Table 3 partial reading-comprehension ability and nonverbal-ability measures from the criterion variables. Performance on the Nelson-Denny reading-comprehension subtest is entered in these hierarchical regressions subsequent to the two nonverbal-ability tasks but prior to the measures of print exposure. By structuring the analyses in this way, we do not mean to imply that print exposure is not a determinant of reading-comprehension ability. Our intent was merely to severely bias the analyses against the print exposure measures. Indeed, we would argue that there are grounds for believing that exposure to print does facilitate growth in comprehension ability (Anderson et al., 1988; Hayes, 1988; Juel, 1988; Stanovich, 1986). Thus, we have allowed the Nelson-Denny comprehension measure to steal some of the variance that rightly belongs to the print exposure measures. The reason for structuring the analyses in this conservative manner was to ensure a stringent test of whether the print exposure measures could predict performance on the criterion variables after possibly spurious relationships with ability were controlled.

The results illustrated in Table 3 indicate that the ART was able to account for additional variance in all of the variables even after reading-comprehension ability had been partialed along with nonverbal ability. Additionally, the ART tended to account for more unique variance than did the other measures of print exposure. The MRT and the favorite-author question accounted for unique variance in four out of five cases. Although the MRT tended to account for more variance, the outcome for the favoriteauthor question is impressive, considering that it is a single item and is scored in a very simple manner. The activity-preference measure was not as good a predictor, even though it did account for unique variance in some of the variables. The reading questionnaire was not a very effective predictor in these analyses.

Overall, the analyses presented in Tables 2 and 3 provide strong evidence that print exposure, independent of comprehension skill and other general abilities, is linked to vocabulary, verbal ability, and general knowledge. The three best predictors (ART, MRT, and the favorite-author question) were able to account for unique variance in vocabulary and general knowledge even when variance explained by reading-comprehension ability-an excellent measure of general verbal ability (Sternberg, 1987; Thomdike, 1973-74)-was removed.

There are, in addition to the hierarchical regression procedures we have employed, additional ways to address the question of whether print exposure indicators are linked to vocabulary and knowledge differences once other abilities have been controlled. The data displayed in Table 4 display the results of one such converging analysis. The performance of two groups of subjects who were similar in general ability but different in amount of print exposure was compared. A nonverbal-ability composite $z$ score was formed by averaging the $z$ scores on the 
Table 4

Differences Between Subjexts High $(n=50)$ and Low $(n=50)$ in Print Exposure Who Are Equated on Reading-Comprehension and Nonverbal Cognitive Ability

\begin{tabular}{lccc}
\hline \multicolumn{1}{c}{ Variable } & $\begin{array}{c}\text { Low } \\
\text { ARTMRTZ }\end{array}$ & $\begin{array}{c}\text { High } \\
\text { ARTMRTZ }\end{array}$ & \multicolumn{1}{c}{$t(98)$} \\
\hline Netson-Denny comprehension & 23.1 & 22.8 & -0.36 \\
Raven matrices & 10.0 & 9.7 & -0.45 \\
Figural analogies & 12.9 & 12.7 & -0.46 \\
ART & .121 & .463 & $13.36 \dagger$ \\
MRT & .321 & .683 & $14.86 \dagger$ \\
ARTMRTZ & -0.99 & 1.12 & $16.24 \dagger$ \\
Favorite-author question & 1.7 & 2.4 & $3.59 \dagger$ \\
Activity preference-reading & 1.3 & 2.2 & $2.50^{*}$ \\
Reading questionnaire & -.07 & .38 & $2.72^{*}$ \\
Nelson-Denny vocabulary & 12.3 & 15.9 & $4.81 \dagger$ \\
PPVT & 8.9 & 14.0 & $7.88 \dagger$ \\
History and literature (NAEP) & 11.1 & 14.7 & $5.17 \dagger$ \\
Spelling composite & -.21 & .35 & $3.20^{*}$ \\
Verbal fluency & 28.3 & 34.2 & $4.08 \dagger$ \\
\hline
\end{tabular}

${ }^{*} p<.05 \quad \dagger p<.001$.

Raven matrices and the figural analogies task. The ARTMRTZ variable (composite of ART and MRT performance) was regressed simultaneously on this composite nonverbal-ability score and Nelson-Denny readingcomprehension subtest. In Table 4, the performance of the 50 subjects with the highest residual scores is compared with the performance of the 50 subjects with the lowest residual scores.

As expected, the groups were not significantly different on the Nelson-Denny comprehension subtest, Raven matrices, or figural analogies task. There were large differences in ART and MRT performance, as well as on ARTMRTZ, which was the defining variable. The various measures of print exposure converged. All displayed significant differences favoring the high ARTMRTZ group. The pattern of differences on the other five variables is again very clear. There were significant differences favoring the high print exposure group on both vocabulary measures, the history/literature knowledge measure, spelling, and verbal fluency. Thus, two groups of subjects in the sample who differed greatly in exposure to print but did not differ in general cognitive ability nevertheless displayed large differences on the criterion variables.

Our sample size was large enough so that it was possible to conduct an analysis that examined the consequences of a mismatch between general cognitive ability and print exposure. Although never losing sight of the correlational nature of the data, we may ask, for example, whether print exposure can compensate for modest levels of general cognitive abilities, at least in a statistical sense. The comparisons presented in Table 5 address this issue. Two groups that were mismatched on print exposure and nonverbal cognitive ability were formed in the following manner. The sample was classified according to a median split of performance on the Raven matrices and on the ARTMRTZ variable. The resulting $2 \times 2$ matrix revealed 118 subjects who were discrepant: 56 subjects who were low in print exposure but high on the Raven (LoPrint/HiAbility) and 62 subjects who were high in print exposure but low on the Raven (HiPrint/LoAbility). These two groups were then compared on all of the variables in the study. Of

Table 5

Differences Between Subjects With High Ability but Low in Print Exposure $(n=56)$ and Subjects With Low Ability but High in Print Exposure $(n=62)$

\begin{tabular}{lccc}
\hline \multicolumn{1}{c}{ Variable } & $\begin{array}{c}\text { LOPRINT/ } \\
\text { HLABILITY }\end{array}$ & $\begin{array}{c}\text { HIPRINT/ } \\
\text { LOABILITY }\end{array}$ & $t(116)$ \\
\hline Raven matrices & 12.7 & 7.9 & $-13.91 \dagger$ \\
Figural analogies & 13.1 & 12.7 & -0.93 \\
ART & .164 & .352 & $9.30 \dagger$ \\
MRT & .433 & .605 & $9.00 \dagger$ \\
ARTMRTZ & -.54 & .55 & $11.87 \dagger$ \\
Favorite-author question & 2.0 & 2.5 & $3.11^{*}$ \\
Activity preference-reading & 1.0 & 1.8 & $2.71^{*}$ \\
Reading questionnaire & -.16 & .19 & $2.20^{*}$ \\
Nelson-Denny vocabulary & 14.3 & 15.5 & 1.90 \\
PPVT & 10.1 & 12.5 & $4.11 \dagger$ \\
History and literature (NAEP) & 12.1 & 13.9 & $3.24^{*}$ \\
Nelson-Denny comprehension & 22.5 & 23.3 & 1.34 \\
Spelling composite & -.16 & .27 & $2.67^{*}$ \\
Verbal fluency & 30.6 & 32.8 & 1.66 \\
\hline${ }^{*} p<.05 \quad \dagger p<.001$. & & &
\end{tabular}


course, there were significant differences on the variables that had defined the groups: the Raven and the ARTMRTZ (as well as its components, ART and MRT). However, this comparison produced converging evidence for our measures of print exposure, because scores on all three of the other print exposure tasks were significantly higher in the HiPrint/LoAbility group. Even more interesting, however, is that the HiPrint/LoAbility group was superior on all of the other variables in the study, significantly so in three cases.

Table 6 displays an analysis of an even more unusual mismatch, that between print exposure and readingcomprehension ability itself. That is, although it is assuredly the case that better readers read more, the correlation between the ability to read and the exercise of that ability is less than perfect. Some individuals read avidly despite modest skills, and others fail to exercise welldeveloped abilities. What are the cognitive correlates of a mismatch between abilities and the exercise of those abilities? To investigate this issue, the sample was classified according to a median split of performance on the NelsonDenny comprehension subtest and on the ARTMRTZ variable. The resulting $2 \times 2$ matrix revealed 82 subjects who were discrepant: 38 subjects who were low in print exposure but high in comprehension (LoPrint/HiComp) and 44 subjects who were high in print exposure but low in comprehension (HiPrint/LoComp). These two groups were then compared on all of the variables in the study. Of course, there were significant differences on the variables that had defined the groups: the Nelson-Denny comprehension and ARTMRTZ (as well as its components, ART and MRT). Although the favorite-author question displayed a significant difference in favor of the HiPrint/ LoComp group, there were no differences on either the activity-preference or reading-questionnaire measures. This result is consistent with the previously reported regression results indicating that the favorite-author question was a more sensitive measure of print exposure than were the other two indicators.
The two groups were not different on the figural analogies measure, but there was a significant difference favoring the LoPrint/HiComp group on the Raven matrices. However, despite the fact that both comprehension differences and nonverbal cognitive abilities favored the LoPrint/HiComp group, LoPrint/HiComp individuals were not superior on any of the other variables. In fact, on one measure of vocabulary (PPVT), the HiPrint/ LoComp group performed significantly better. It appears that print exposure can compensate for modest levels of general cognitive abilities, at least in a statistical sense. Although inferences from these correlational analyses must be tentative, the results do suggest that low ability need not necessarily hamper the development of vocabulary and verbal knowledge as long as the individual is exposed to a lot of print.

\section{DISCUSSION}

The present study provided ample evidence that exposure to print is associated with verbal skill and declarative knowledge. All five measures of print exposure (ART, MRT, favorite-author question, activity-preference scale, and reading questionnaire) displayed significant zero-order correlations with measures of vocabulary, cultural knowledge, spelling, and verbal fluency. Furthermore, it was demonstrated that the link between print exposure and these cognitive outcomes is not entirely mediated by general cognitive ability.

Certainly, it is the case that individuals high in cognitive ability read more-all the measures of print exposure in our study were correlated with the nonverbal-ability measures and with reading-comprehension skill. But if these print exposure indicators were just proxies for general ability, they could not account for variance in cognitive outcomes once the influence of general ability was removed. In fact, this was not the case. Across a variety of different analyses that controlled for ability level, print exposure remained a robust predictor of the criterion vari-

Table 6

Differences Between Subjects High in Comprehension Ability but Low in Print Exposure $(n=38)$ and Subjects Low in Comprehension Ability but High in Print Exposure $(n=44)$

\begin{tabular}{lccr}
\multicolumn{1}{c}{ Variable } & $\begin{array}{c}\text { LOPRINT/ } \\
\text { HICOMP }\end{array}$ & $\begin{array}{c}\text { HIPRINT/ } \\
\text { LOCOMP }\end{array}$ & $t(80)$ \\
\hline Nelson-Denny comprehension & 25.3 & 20.9 & $-11.47 \dagger$ \\
ART & .186 & .310 & $5.27 \dagger$ \\
MRT & .444 & .630 & $9.73 \dagger$ \\
ARTMRTZ & -.44 & .49 & $10.39 \dagger$ \\
Favorite-author question & 2.1 & 2.5 & $2.29^{*}$ \\
Activity preference-reading & 1.7 & 1.3 & -0.90 \\
Reading questionnaire & .11 & .05 & -0.32 \\
Raven matrices & 10.7 & 9.0 & $-2.44^{*}$ \\
Figural analogies & 13.1 & 12.9 & -0.30 \\
Nelson-Denny vocabulary & 15.1 & 14.4 & -0.94 \\
PPVT & 10.6 & 12.1 & $2.06^{*}$ \\
History and literature (NAEP) & 12.7 & 13.4 & 0.99 \\
Spelling composite & .16 & -.05 & -1.12 \\
Verbal fluency & 31.6 & 32.0 & 0.30 \\
\hline
\end{tabular}

${ }^{*} p<.05 \quad+p<.001$ 
ables. With one minor exception, all of the print exposure measures proved to be significant unique predictors of the cognitive outcomes after two nonverbal-ability measures were entered first into the regression equations. The ART, MRT, and the favorite-author measure maintained their ability to predict unique variance even after Nelson-Denny comprehension was added to the prior variables forced into the equation (Table 3 ). These results represent extremely strong evidence because of the conservatism inherent in the logic of the analyses. By allowing reading comprehension to enter the equation first, we adopted an implicit model whereby all of the linkage between comprehension and print exposure is assumed to be due to the causal effects of the former on the latter. This, of course, is a model that we do not endorse (Stanovich, 1986). But if the unique effects of print exposure as a predictor of vocabulary and other outcomes can survive such a causally misspecified analysis, then surely these data have refuted the argument that print exposure is merely a proxy for cognitive ability and that any linkage with vocabulary or knowledge is spurious. In the absence of a true experiment, this is probably the strongest evidence we are going to get.

These data refute the argument that experiential factors are not implicated-or are of secondary importance-in explaining performance on vocabulary measures. For example, Sternberg (1985) has argued that

simply reading a lot does not guarantee a high vocabulary. What seems to be critical is not sheer amount of experience but rather what one has been able to learn from and do with that experience. According to this view, then, individual differences in knowledge acquisition have priority over individual differences in acnal knowledge. (p. 307)

Jensen (1980) has argued the point even more strongly, stating:

Children of high intelligence acquire vocabulary at a faster rate than children of low intelligence, and as adults they have a much larger than average vocabulary, not primarily because they have spent more time in study or have been more exposed to words, but because they are capable of educing more meaning from single encounters with words. ... The vocabulary test does not discriminate simply between those persons who have and those who have not been exposed to the words in context. ... The crucial variable in vocabulary size is not exposure per se, but conceptual need and inference of meaning from context, which are forms of eduction. Hence, vocabulary is a good index of intelligence. (pp. 146-147)

The analyses reported here would seem to refute this argument if it is accepted that the variables entered prior to print exposure in Table 3 are reasonable measures of general cognitive ability.

The data can be partitioned in additional ways that are informative on this issue. For example, it certainly seems reasonable to consider reading comprehension as a generalability measure strongly related to skill in inducing word meanings. Sternberg (1987) so argues:
Whereas vocabulary is an indirect measure of ability to learn word meanings in context, reading comprehension is a fairly direct measure of ability to learn concepts in context. ... The major difference would then be that reading comprehension tests measure present ability to learn from context, whereas vocabulary tests measure past ability. (p. 90)

Yet consider what a commonality analysis (Kerlinger \& Pedhazur, 1973) reveals about the extent of overlap in variance among reading comprehension, print exposure, and vocabulary (see Table 7). It is true that reading comprehension and print exposure overlap considerably in the variance that they shared with vocabulary measures $(.227$ and 295 , for the PPVT and Nelson-Denny vocabulary, respectively). However, the print exposure measure (ARTMRTZ) explains as much unique variance as does reading comprehension on the Nelson-Denny vocabulary measure and explains considerably more unique variance than reading comprehension when the vocabulary measure is the PPVT. Table 8 indicates that even when reading-comprehension ability is amalgamated with the Raven and figural analogies tasks into a set of variables indexing general ability, the same relationships obtain. Print exposure remains separable from general ability and has as much unique predictive power as does the ability composite.

It is true that two of the print exposure indicators (the activity-preference measure and the reading questionnaire) were not unique predictors in some of these analyses. However, these two measures were very brief (the readingquestionnaire composite consisting of only two items). Low reliabilities, combined with the conservative nature of the analyses, probably accounted for the inability to

Table 7

Commonality Analysis of Vocabulary, Comprehension, and Print Exposure

Unique Common

Dependent Variable: PPVT

Nelson-Denny comprehension $\quad .024 \quad .227$ ARTMRTZ

.220

Dependent Variable: Nelson-Denny Vocabulary

Nelson-Denny comprehension $\quad .121 \quad .295$

\begin{tabular}{lll} 
ARTMRTZ & .112 & .295 \\
\hline
\end{tabular}

Table 8

Commonality Analysis of Vocabulary, General Ability, and Print Exposure

Unique Common

Dependent Variable: PPVT

General ability $\quad .036 \quad .257$

$\begin{array}{lll}\text { ARTMRTZ } & .190 & .257\end{array}$

Dependent Variable: Nelson-Denny Vocabulary

\begin{tabular}{lll} 
General ability & .149 & 319 \\
\hline
\end{tabular}

\begin{tabular}{ll} 
ARTMRTZ & .088 \\
\hline
\end{tabular} tion of variance on Raven matrices, figural analogies, and Nelson-Denny comprehension performance. 
explain unique variance in some cases. In contrast to the activity-preference and reading-questionnaire measures, which were sometimes weak predictors, the favoriteauthor question was a moderate predictor despite being only one question and despite its fairly crude scoring procedure. Finally, the ART and MRT were consistently powerful and robust unique predictors. These are clearly our best measures of print exposure, and from this standpoint, the other three measures should probably be looked on as converging indicators, helpful in establishing the convergent validity of the ART and MRT and ensuring that the general patterns uncovered by the ART and MRT replicate with at least one other measure of print exposure with very different response/cognitive requirements.

Some further indications that these recognition measures were sensitive indicators can be gleaned by a perusal of Appendixes A and B. First, individual items were sensitive to sex differences in reading habits. Appendix A presents the percentage of times that males and females checked each of the items on the ART (there were no significant sex differences in foil checking). There were significant sex differences on some of the items. Certain authors of "female" genres were recognized to a greater extent by females (e.g., Barbara Cartland, Judith Krantz, Colleen McCullough, Danielle Steel), and certain authors of "male" genres were recognized to a significantly greater extent by males (e.g., Isaac Asimov, Arthur Clarke, Ian Fleming, Frank Herbert, Louis L'Amour, Robert Ludlum). A similar outcome obtained for the MRT. Certain magazines were recognized to a greater extent by females (e.g., Ladies Home Journal, Mademoiselle, McCall's, Redbook, Seventeen), and others were recognized to a greater extent by males (e.g., Car and Driver, Esquire, Field \& Stream, Gentlemen's Quarterly, Motor Trend, The Sporting News), with the items displaying differences highly sex-typed with respect to content.

Other aspects of the item data presented in Appendixes $A$ and $B$ indicate why these measures were such potent predictors. The last two columns of these appendixes show the percentage recognition for each item for subjects scoring low and high on the PPVT, based on a median split of performance on that task. It is clear that, in many cases, performance on an individual item can differentiate the groups. Specifically, on the ART, the subjects with high scores on the PPVT significantly outperformed the lowPPVT subjects on 32 of the $\mathbf{4 0}$ items. In only one case did a higher proportion of low-PPVT subjects recognize an item (there was no difference between the groups in foil checking). The outcome on the MRT was similar. The subjects with high scores on the PPVT significantly outperformed the low-PPVT subjects on 29 of the 40 items. In not one single case did a higher proportion of lowPPVT subjects recognize an item (this despite the fact that low-PPVT subjects checked significantly more foils on this task). If individual items can significantly differentiate high- and low-vocabulary subjects, it is no wonder that the composite scale is a robust predictor.

Why are the ART and MRT particularly good measures of print exposure? Previous studies, as well as our own data presented here, have indicated that more conventional questionnaire methods have yielded much weaker correlations (Nell, 1988; Stanovich \& West, 1989; Walberg \& Tsai, 1984). Our conjecture is that the unique diagnosticity of the ART and MRT derives from their use of a logic that completely circumvents socially desirable responding (Furnham, 1986). Previous research has indicated that socially desirable responding is occurring on reading-habits questionnaires (Zill \& Winglee, 1990). Ennis (1965) reports statistics indicating that $38 \%$ of a sample who read only 1-4 books per year reported themselves as "moderate" to "heavy" readers. Indeed, even $18 \%$ of those who read no books in the last year characterized themselves as "moderate" to "heavy" readers. Ennis (1965) concludes that "it is not clear what ... makes people call themselves readers when in fact they read very few books"' (p. 47).

Of course, in correlational work, the key issue is one of differential tendencies toward socially desirable responses rather than the absolute level of such responding. Nevertheless, correlational relationships may still be obscured by this factor. Thus, in circumventing the socialdesirability confound-a confound that may be particularly prevalent in the responses of college students who are clearly aware that parents, teachers, and professors value reading - the ART and MRT have a tremendous advantage over other, more traditional, questionnaire methods. Although checklist procedures have been used before to assess print exposure (Chomsky, 1972; Huck, 1966), they have not been employed in the context of a method that uses foils to control for guessing and differential-response criteria.

In light of our argument that it is the control for social desirability that accounts for the diagnosticity of the recognition checklists, it is interesting to note that after the ART and MRT, the next best predictor was the favorite-author question. This variable was consistently more of a unique predictor than either the activity-preference measure or the reading questionnaire (see also Stanovich \& West, 1989). This was particularly apparent in the analyses shown in Table 3, in which reading-comprehension ability was partialed along with the nonverbal-ability measures. The favorite-author question, like the ART and MRT, is a performance measure, not a subjectivepreference measure. Similar to the ART and MRT, but unlike the other two, the favorite-author question cannot be faked. Either the subjects know three authors to write down or they do not. It is this property, we conjecture, that accounts for its ability to predict unique variance in the criterion variables. Finally, the activity-preference measure was a better indicator than the reading questionnaire, perhaps because the former required the subject to make a forced choice among activities, thus at least partially obscuring social-desirability cues.

As previously noted in the discussion of Table 1, the ART displayed larger correlations with the outcome variables than did the MRT, and it consistently accounted for more unique variance. An even more powerful way of illustrating their differential diagnosticity is displayed in 
Table 9

Differences Between Subjects Scoring Low on the ART and High on the MRT $(n=41)$ and Subjects Scoring High on the ART and Low on the MRT $(n=35)$

\begin{tabular}{lccc}
\hline \multicolumn{1}{c}{ Variable } & $\begin{array}{c}\text { LoART/ } \\
\text { HiMRT }\end{array}$ & $\begin{array}{c}\text { HiART/ } \\
\text { LoMRT }\end{array}$ & \multicolumn{1}{c}{$(74)$} \\
\hline ART & .172 & .348 & $11.06 \dagger$ \\
MRT & .614 & .434 & $-10.77 \dagger$ \\
Favorite-author question & 2.0 & 2.5 & $2.50^{*}$ \\
Activity preference-reading & 1.1 & 1.8 & 1.71 \\
Reading questionnaire & -.29 & .22 & $2.47^{*}$ \\
Raven matrices & 10.3 & 11.0 & 1.14 \\
Figural analogies & 12.7 & 12.7 & 0.01 \\
Nelson-Denny vocabulary & 14.3 & 16.1 & $2.45^{*}$ \\
PPVT & 11.1 & 12.7 & $2.03^{*}$ \\
History and literature (NAEP) & 12.4 & 14.6 & $3.75 \dagger$ \\
Nelson-Denny comprehension & 22.4 & 24.2 & $3.01 \dagger$ \\
Spelling composite & -.32 & .42 & $3.93 \dagger$ \\
Verbal fluency & 29.6 & 33.3 & $2.20^{*}$ \\
\hline
\end{tabular}

${ }^{*} p<.05 \quad+p<.01$.

the data presented in Table 9. To obtain the two subsamples displayed there, the entire sample was classified according to a median split of performance on the ART and MRT. The resulting $2 \times 2$ matrix revealed 76 subjects who were discrepant: 41 subjects were low on the ART but high on the MRT, and 35 subjects were high on the ART and low on the MRT (note that this is in a relative sense only-performance on the MRT was uniformly higher than that on the ART). Interestingly, all three of the other measures of print exposure displayed differences favoring the HiART/LOMRT group, two of them significantly so. No differences were apparent on either of the nonverbalability measures. However, the HiART/LoMRT group scored significantly higher on all six of the other outcome measures.

The two tasks do not differ in their reliabilities, so that is not the explanation for these differences. We believe that the superior performance of the HiART/LOMRT group occurs because the ART primarily taps bookreading. Although some of the authors on the ART write for newspapers and magazines, familiarity with these writers is most likely due to their names being encountered in books. Thus, relative to magazine reading, exposure to books appears to be more related to positive verbal outcomes. Previous studies have found bookreading to be a better predictor of various educational outcomes than either magazine or comic-book reading (Anderson et al., 1988; Greaney, 1980; Kirsch \& Jungeblut, 1986; Nell, 1988). Perhaps there are differences in depth of processing typically associated with different types of reading material, with magazines being more likely to elicit shallow processing. Uninvolved page-turning more commonly occurs with magazines, and pictures are also more prominent in magazines. Alternatively, encounters with magazines may be more haphazard, more likely to occur through the electronic media or in public places such as doctors' offices.
The difference in the relative diagnosticity of the ART and MRT prompts speculations about some of the other characteristics of the recognition-checklist methodology. We may admit the drawbacks of these measures while at the same time recognizing their potential to serve as quick probes of individual differences in print exposure. For example, it is clear that these checklist tasks will not measure absolute levels of print exposure with respect to time spent reading or number of words read. Other methods, such as the collection of activity diaries (Anderson et al., 1988; Greaney, 1980; Guthrie \& Greaney, 1991; Kirsch \& Guthrie, 1984; Rice, 1986; Taylor et al., 1990), will be necessary to obtain these estimates. The checklist measures only reflect relative individual differences in exposure to print. That is sufficient in most correlational studies, but for some purposes, such as estimating growth in absolute vocabulary size due to reading (e.g., Anderson et al., 1988; Nagy \& Anderson, 1984; Nagy, Herman, \& Anderson, 1985), absolute time estimates may be necessary.

The fact that the measures are very indirect proxy indicators is, of course, problematic in some contexts, but, alternatively, it is sometimes a strength. Clearly, hearing about a magazine or author on television without having been exposed to the actual written work is problematic. The occurrence of this type of situation obviously reduces the validity of the tasks. However, consider a postexperimental comment sometimes made by subjects: They knew a certain name was that of an author but had never read anything that the author had written. When questioned on how they knew that the name was that of a writer, the subjects often replied that they had seen one of the author's books in a bookstore, had seen an author's book in the "new fiction" section at the library, had read a review of the author's work in Newsweek, had seen an advertisement in the newspaper, and so forth. In short, knowledge of that author's name was a proxy for reading activities, despite the fact that the particular author had not actually been read. This factor might be one reason why the ART and MRT work so well. There certainly are ways (e.g., TV and radio) of gaining familiarity with the names that would reduce validity. However, most behaviors leading to familiarity with authors' names are probably themselves proxies for reading.

\section{CONCLUSIONS}

What are the mechanisms by which print exposure comes to be an independent predictor of variance in the criterion variables studied in this investigation? There are, in fact, several possible mechanisms by which print exposure could become a mechanism of cognitive change. First, the distributions of language structures that people are exposed to in print are different from those that people encounter in speech. Evidence for this conjecture is most strong in the lexical domain. Work by Hayes (1988; Hayes \& Ahrens, 1988; see also Biber, 1986; Chafe \& 
Danielewicz, 1987; Corson, 1985) has indicated that moderate-to-low-frequency words-precisely those words that differentiate individuals of high and low vocabulary size-appear much more often in common reading matter than in common speech.

To a lesser extent, a similar situation holds for other language systems, including syntax (Purcell-Gates, 1988). Although it is true that all syntactic constructions can be found in all types of language, more complex syntactic constructions are disproportionately found in text (Biber, 1986; Redeker, 1984). This is not to deny that complex syntactic constructions are also found disproportionately in types of speech that are text-like, such as judicial proceedings, planned speeches, and college lectures (Biber, 1986; Chafe \& Danielewicz, 1987)-it is only to establish that the average person experiences these syntactic constructions disproportionately in print (Chafe \& Danielewicz, 1987; Purcell-Gates, 1988; Redeker, 1984). In short, print exposure might be expected to contribute to skill in verbal domains because print is an exceptional source of rich stimulation.

Another mechanism by which print exposure might lead to cognitive change is its role as a builder of the individual's knowledge base. In recent years, cognitive and developmental psychologists have strongly emphasized the importance of domain knowledge in determining processing efficiency (Ceci, 1990; Chi, Hutchinson, \& Robin, 1989; Keil, 1984; Scribner, 1986). To the extent that we endorse cognitive theories that view individual differences in basic processing capacities as at least partly determined by differences in knowledge bases (e.g., Ceci, 1990), then print exposure piggybacks on these theories. This is because print exposure is a unique source of world knowledge. Personal experience provides only narrow knowledge of the world and is often misleading and unrepresentative (Dawes, 1988; Gilovich, 1991; Nisbett \& Ross, 1980). The most commonly used electronic sources of information (television, radio) lack depth (Hayes \& Ahrens, 1988; Postman, 1985). Only print provides opportunities for acquiring broad and deep knowledge of the world. Research indicates that reading displays higher correlations with world and cultural knowledge than does television viewing (West \& Stanovich, 1991; Zill \& Winglee, 1990). Thus, domain-knowledge theories indirectly provide a mechanism through which print exposure influences cognitive efficiency. Print is simply a more distal factor that determines individual differences in knowledge bases that in turn influence performance on a variety of "basic" information processing tasks (see Ceci, 1990).

Much work remains to be done in developing a complete model of the relationships between reading habits and cognitive abilities. For example, the role of literacy in developing decontextualized thinking skills is particularly controversial (Akinnaso, 1981; Goody, 1977, 1987; Nystrand, 1986, 1987; Olson, 1977, 1986; Ong, 1982) and is badly in need of empirical investigation. Never- theless, taken collectively, our results suggest that print exposure, although clearly a consequence of developed reading ability, is probably a significant contributor to the development of aspects of verbal intelligence. Reading volume is thus an explanatory variable that should be more routinely considered when attempting to predict individual cognitive outcomes and group trends. For example, print exposure might be a useful explanatory variable that can be used to explain group trends such as declining verbal SAT scores (Wirtz, 1977) or historical changes in intelligence-test performance (Flynn, 1987).

Similarly, when speculating about variables in people's ecologies that could account for cognitive change-in an attempt to supplement purely genetic accounts of mental ability (e.g., Ceci, 1990)-it may be worthwhile to consider print exposure. In this case, the variables that are chosen for examination must be those that can have longterm effects because of their repetitive and/or cumulative action. Schooling is obviously one such variable (Cahan \& Cohen, 1989; Ceci, 1990). However, print exposure is another variable that cumulates over time into enormous individual differences. For example, Anderson et al. (1988) have found hundredfold differences in word exposure among fifth-grade children and order of magnitude differences in opportunities to learn vocabulary words (see also Hayes \& Ahrens, 1988).

In summary, we have reported a first step in the development of a methodology that can track the specific cognitive correlates of literacy with perhaps more quantitative precision than has been accomplished to date. Despite many plausible reasons for believing that there are cognitive effects of differential exposure to print, there are actually very few empirical demonstrations relating print exposure specifically to cognitive outcomes in the verbal domain. The literature that does exist tends to report only zero-order correlations (e.g., Nell, 1988) that admit many alternative explanations. Our research adds to the surprisingly meager evidence that links differences in reading volume to verbal intelligence after general ability correlates are controlled (see Anderson et al., 1988).

We have demonstrated that there is enough isolable variance within a generally literate society to link with cognitive differences. Research in this area will be facilitated if it is not always necessary to obtain totally illiterate samples or to set up cross-cultural comparisons. It is immensely difficult to separate the effects of literacy from those of schooling in studies comparing literates with illiterates (Scribner \& Cole, 1981). If at least somewhat analogous issues to those raised in the cross-cultural research can be studied within literate societies, the speed with which we can answer questions about the cognitive consequences of literacy could be greatly increased because more studies could be carried out, larger samples could be studied, and the range of the cognitive domains tapped could be widened. 


\section{REFERENCES}

AkinNaso, F. N. (1981). The consequences of literacy in pragmatic and theoretical perspectives. Anthropology \& Education Quarterly. 12, $163-200$.

Anderson, R. C., Wilson, P. T. . Fielding, L. G. (1988). Growth in reading and how children spend their time outside of school. Reading Research Quarterly, 23, 285-303.

BiBER, D. (1986). Spoken and written textual dimensions in English: Resolving the contradictory findings. Language, 62, 384-414.

Brown, J., Bennett, J., Hanna, G. (1981). The Nelson-Denny Reading Test. Lombard, IL: Riverside.

Cahan, S., Cohen, N. (1989). Age versus schooling effects on intelligence development. Child Development, 60, 1239-1249.

Carprenter, P. A., Just, M. A., Shell, P. (1990). What one intelligence test measures: $A$ theoretical account of the processing in the Raven Progressive Matrices Test. Psychological Review, 97, 404-431.

CARr, T. H., LEVY, B. A., (Eds.) (1990). Reading and its development: Component skills approaches. San Diego: Academic Press.

CECI, S. J. (1990). On incelligence ... more or less: A bio-ecological treatise on intellectual development. Englewood Cliffs, $\mathrm{NJ}$ : Prentice-Hall.

Chafe, W., Danielewicz, J. (1987). Properties of spoken and writuen language. In R. Horowitz \& S. J. Samuels (Eds.), Comprehending oral and written language (pp. 83-113). San Diego: Academic Press.

Chi, M. T. H., Hutchinson, J. E., Robin, A. F. (1989). How inferences about novel domain-related concepts can be constrained by structured knowledge. Merrill-Palmer Quarterly, 35, 27-62.

CHOMsKY, C. (1972). Stages in language development and reading exposure. Harvard Educational Review, 42, 1-33.

Corson, D. (1985). The lexical bar. Oxford: Pergamon Press.

Cunningham, A. E., Stanovich, K. E. (1990). Assessing print exposure and orthographic processing skill in children: A quick measure of reading experience. Journal of Educational Psychology, 82, 733-740.

Cunningham, A. E., \&tanovich, K. E. (1991). Tracking the unique effects of print exposure in children: Associations with vocabulary, general knowledge, and spelling. Joumal of Educational Psychology, 83, 264-274.

DANEmAN, M. (1991). Individual differences in reading skills. In R. Barr, M. L. Kamil, P. Mosenthal, \& P. D. Pearson (Eds.), Handbook of reading research (Vol. 2. pp. 512-538). New York: Longman.

DAwEs, R. M. (1988). Rational choice in an unceriain world. San Diego: Harcourt Brace Jovanovich.

Dunn, L. M., Dunn, L. M. (1981). Peabody Picture Vocabulary Test-Revised. Circle Pines, MN: American Guidance Service.

Dunn, L. M., * Markward, F. C. (1970). Peabody Individual Achievement Test. Circle Pines, MN: American Guidance Service.

ENNIS, P. H. (1965). Adult book reading in the United States (Report No. 105). Chicago: University of Chicago, National Opinion Research Center.

EsTES, T. H. (1971). A scale to measure attitudes toward reading. Joumal of Reading, 15, 135-138.

Fischer, F. W., Shankweiler, D., \& Liberman, I. Y. (1985). Spelling proficiency and sensitivity to word structure. Joumal of Memory \& Language, 24, 423-441

FlYNN, J. R. (1987). Massive IQ gains in 14 nations: What IQ tests really measure. Psychological Bulletin, 101, 171-191.

Fuller, B., Edwards, J., Gorman, K. (1987). Does rising literacy spark economic growth? Commercial expansion in Mexico. In D. A. Wagner (Ed.), The future of literacy in a changing world (pp. 319. 340). Oxford, U.K.: Pergamon Books.

Furnham, A. (1986). Response bias, social desirability and dissimulation. Personality \& Individual Differences, 7, 385-400.

GEE, J. P. (1988). The legacies of literacy: From Plato to Freire through Harvey Graff. Harvard Educational Review, 58, 195-212.

Glovich, T. (1991). How we know what isn' so. New York: Free Press.

Goody, J. (1977). The domestication of the savage mind. New York: Cambridge University Press.

Goody, J. (1987). The interface between the written and the oral. Cambridge: Cambridge University Press.
GrafF, H. J. (1986). The legacies of literacy: Continuities and contradictions in western society and culture. In S. de Castell, A. Luke, \& K. Egan (Eds.), Literacy, society, and schooling (pp. 61-86). Cambridge: Cambridge University Press.

GrafF, H. J. (1987). The labyrinths of liveracy. London: Falmer Press.

GreaneY, V. (1980). Factors related to amount and time of leisure time reading. Reading Research Quarterly, 15, 337-357.

Greaney, V., \& Hegarty, M. (1987). Correlates of leisure-time reading. Journal of Research in Reading, 10, 3-20.

GreEnfIELD, P. (1972). Oral or written language: The consequences for cognitive development in Africa, the United States and England. Language \& Speech, 15, 169-178.

GutHRE, J. T. (1981). Reading in New Zealand: Achievement and volume. Reading Research Quarterly, 17, 6-27.

Guthrie, J. T., Greaney, V. (1991). Literacy acts. In R. Bart, M. L. Kamil, P. Mosenthal, \& P. D. Pearson (Eds.), Handbook of reading research (Vol. 2, pp. 68-96). New York: Longman.

Guthrie, J. T., SEIfERT, M. (1983). Profiles of reading activity in a community. Journal of Reading, 26, 498-508.

Havelock, E. A. (1963). Preface to Plato. Cambridge: Harvard University Press.

Havelock. E. A. (1980). The coming of literate communication to Westem culture. Joumal of Communication, 30, 90-98.

HAYES, D. P. (1988). Speaking and writing: Distinct parterns of word choice. Joumal of Memory \& Language, 27, 572-585.

HaYes, D. P., Ahrens, M. (1988). Vocabulary simplification for children: A special case of 'motherese'? Jourmal of Child Language, 15, 395-410.

HuCK, C. S. (1966). Taking inventory of children's literary background. Glenview, IL: Scott-Foresman.

Jackson, M., MCClelland, J. (1979). Processing determinants of reading speed. Joumal of Experimental Psychology: General, 108, $151-181$.

JASTAK, S., WILKInson, G. S. (1984). Wide Range Achievement Test-Revised. Wilmington, DE: Jastak Associates.

Jensen, A. (1980). Bias in mental testing. New York: Free Press.

JUEL, C. (1988). Learning to read and write: A longitudinal study of 54 children from first through fourth grades. Joumal of Educational Psychology, 80, 437-447.

JUST, M., \& CARPENTER, P. A. (1987). The psychology of reading and langunge comprehension. Boston: Allyn \& Bacon.

Kaest LE, C. F. (1991). Literacy in the United States. New Haven, CT: Yale University Press.

KEIL, F. C. (1984). Mechanisms of cognitive development and the structure of knowledge. In R. Sternberg (Ed.), Mechanisms of cognitive development (pp. 81-99). New York: W. H. Freeman.

Kerlinger, F. N., PedhazUr. E. J. (1973). Multiple regression in behavioral research. New York: Holt, Rinehart \& Winston.

Kursch, I. S., \& Guthrie, J. T. (1984). Prose comprehension and text search as a function of reading volume. Reading Research Quarterly, 19. 331-342.

Kirsch, I., \& Jungeblut, A. (1986). Literacy: Profiles of America's young adults. Princeton, NJ: Educational Testing Service.

LewIS, R., TeaLE, W. H. (1980). Another look at secondary school students' attitudes toward reading. Joumal of Reading Behavior, 12. 187-201.

LURIA, A. R. (1976). Cognitive development: Its cultural and social foundations. Cambridge, MA: Harvard University Press.

MANNING, M. (Ed.) (1988). The standard periadical directory (11th ad.). New York: Oxbridge Communications.

morais, J., Bertelson, P., CAry, L., * Alrgena, J. (1986). Literacy training and speech segmentation. Cognition, 24, 45-64.

NAGY, W. E., \& ANDERson, R. C. (1984). How many words are there in printed school English? Reading Research Quarnerly, 19, 304-330.

NaGy, W. E., Herman, P. A., * Anderson, R. C. (1985). Learning words from context. Reading Research Quarterly, 20, 233-253.

NELL, V. (1988). The psychology of reading for pleasure: Needs and gratification. Reading Research Qwarterly, 23, 6-50.

NISBETT, L., * Ross, L. (1980). Human inference: Strategies and shortcomings of social judgment. Englewood Cliffs, NJ: Prentice-Hall.

NYSTRAND, M. (1986). The structure of written communication: Studies 
in reciprocity between writers and readers. Orlando, FL: Academic Press.

NYSTRAND, M. (1987). The role of context in written communication. In R. Horowizz \& S. J. Samuels (Eds.), Comprehending oral and written language (pp. 197-214). San Diego: Academic Press.

OLSON, D. R. (1977). From utterance to text: The bias of language in speech and writing. Harvard Educational Review, 47, 257-281.

Ouson, D. R. (1986). The cognitive consequences of literacy. Canadian Psychology, 27, 109-121.

Osson, D. R. (1987). An introduction to understanding literacy. Interchange, 18, 1-8.

OLson, D. R. (1988). Mind and media: The epistemic functions of literacy. Joumal of Communication, 38, 27-36.

ONG, W. J. (1967). The presence of the word. Minneapolis: University of Minnesota Press.

ONG, W. J. (1982). Orality and literacy. London: Methuen.

PAulhus, D. L. (1984). Two-component models of socially desirable responding. Joumal of Personality \& Social Psychology, 46, 598-609.

Pellegrino, J. W., Glaser, R. (1979). Cognitive correlates and components in the analysis of individual differences. In $\mathbf{R}$. $\mathbf{J}$. Sternberg \& D. K. Detterman (Eds.), Human intelligence: Perspectives on its theory and measurement (pp. 61-88). Norwood, NJ: Ablex.

Perfett1, C. A. (1985). Reading ability. New York: Oxford University Press.

Petrerson's Guides (1990). Peterson's guide to four-year colleges (21st Ed.). Princeton, NJ: Peterson's Guides.

Postman, N. (1985). Amusing ourselves to death. New York: Viking Penguin.

Purcell-Gates, V. (1988). Lexical and syntactic knowledge of written narrative held by well-read-to kindergartners and second graders. Research in the Teaching of English, 22, 128-157.

RAven, J. C. (1962). Advanced Progressive Matrices (Set II). London: H. K. Lewis.

RAven, J. C., Court, J. H., \& RAveN, J. (1977). Manual for Aduanced Progressive Matrices (Sets I \& II). London: H. K. Lewis \& Co.

Ravirch, D., FinN, C. E. (1987). What do our 17-year-olds know? New York: Harper \& Row.

RAYNer, K., Pollatsek, A. (1989). The psychology of reading. Englewood Cliffs, NJ: Prentice Hall.

ReDEKER, G. (1984). On differences between spoken and written language. Discourse Processes, 7, 43-55.

Rice, G. E. (1986). The everyday activities of adults: Implications for prose recall: I. Educational Gerontology, 12, 173-186.

SCINTo, L. (1986). Written language and psychological development. Orlando, FL: Academic Press.
SCribner, S. (1986). Thinking in action: Some charecteristics of practical thought. In R. J. Sternberg \& R. K. Wagner (Eds.), Practical intelligence (pp. 13-30). Cambridge: Cambridge University Press.

SCRJgner, S., COLE, M. (1978). Literacy without schooling: Testing for intellectual effects. Harward Educarional Review, 48, 448-461.

SCRIBNER, S., C COLE, M. (1981). The psychology of literacy. Cambridge, MA: Harvard University Press.

Sharon, A. T. (1973-1974). What do adults read? Reading Research Quarterly, 9, 148-169.

SincofF, J. B., STERnBerg, R. J. (1987). Two faces of verbal ability. Intelligence, 11, 263-276.

Snodgrass, J. G., CoRWTN, J. (1988). Pragmatics of measuring recognition memory: Applications to dementia and amnesia. Joumal of $E x$ perimental Psychology: General, 117, 34-50.

Stanovich, K. E. (1986). Matthew effects in reading: Some consequences of individual differences in the acquisition of literacy. Reading Research Quarterly, 21, 360-407.

Stanovich, K. E., \& West, R. F. (1989). Exposure to print and orthographic processing. Reading Research Quarerly, 24, $402-433$.

STERNBERG, R. J. (1985). Beyond IQ: A triarchic theory of human in telligence. Cambridge: Cambridge University Press.

StERNBERG, R. J. (1987). Most vocabulary is learned from context. In M. G. Mckeown \& M. E. Curtis (Eds.), The nature of vocabslary acquisition (pp. 89-105). Hillsdale, NJ: Erlbaum.

StERNBERG, R. J. (1988). The triarchic mind: A new theory of human intelligence. New York: Viking.

SternberG, R. J. (1990). Metaphors of mind: Conceptions of the nature of inielligence, Cambridge: Cambridge University Press.

Stock, B. (1983). The implications of literacy. Princeton, NJ: Princeton University Press.

TAYlor, B. M., Frye, B. J., Maruyama, G. M. (1990). Time spent reading and reading growth. American Educational Research Journal, 27, 351-362.

THORNDIKE, R. L. (1973-1974). Reading as reasoning. Reading Research Quarterly, 9, 135-147.

WAGNER, D. A. (1987). Literacy futures: Five common problems from industrializing and developing countries. In D. A. Wagner (Ed.), the future of literacy in a changing world (pp. 3-16). Oxford: Pergamon.

WALBERG, H. J., \& TSA, S. (1984). Reading achievement and diminishing renims to time. Joumal of Educational Psychology, 76, 442-451.

WEst, R. F., \& STANoviCH, K. E. (1991). The incidental acquisition of information from reading. Psychological Science, 2, 325-330.

WIRTz, W. (1977). On further examination. New York: College Entrance Examination Board.

ZILL, N., WINGLEE, M. (1990). Who reads literature? Cabin John, MD: Seven Locks Press.

APPENDIX A

Percentage Recognition of Authors on the ART

\begin{tabular}{lccccc}
\hline \multicolumn{1}{c}{ Author } & $\begin{array}{c}\text { Overall } \\
\text { Mean }\end{array}$ & Male & Female & $\begin{array}{c}\text { Lo } \\
\text { PPVT }\end{array}$ & $\begin{array}{c}\text { Hi } \\
\text { PPVT }\end{array}$ \\
\hline Maya Angelou & 19.7 & 12.3 & $24.2^{*}$ & 18.5 & 21.0 \\
Isaac Asimov & 60.0 & $75.4 \dagger$ & 50.5 & 38.9 & $83.2 \dagger$ \\
Jean Auel & 11.7 & 9.6 & 12.9 & 5.1 & $18.9 \dagger$ \\
James Baldwin & 36.7 & 40.4 & 34.4 & 31.8 & 42.0 \\
Judy Blume & 83.0 & 74.6 & $88.2 \dagger$ & 75.2 & $91.6 \dagger$ \\
Jacob Bronowski & 2.0 & 0.9 & 2.7 & 2.5 & 1.4 \\
Anthony Burgess & 14.3 & 17.5 & 12.4 & 7.0 & $22.4 \dagger$ \\
Edgar Rice Burroughs & 21.0 & $27.2^{*}$ & 17.2 & 10.2 & $32.9 \dagger$ \\
Barbara Cartland & 14.7 & 4.4 & $21.0 \dagger$ & 8.9 & $21.0 \dagger$ \\
Arthur C. Clarke & 25.3 & $39.5 \dagger$ & 16.7 & 12.7 & $39.2 \dagger$ \\
James Clavell & 34.3 & $42.1^{*}$ & 29.6 & 14.0 & $56.6 \dagger$ \\
Peter Drucker & 1.7 & 0.9 & 2.2 & 0.6 & 2.8 \\
Ian Fleming & 62.0 & $76.3 \dagger$ & 53.2 & 43.3 & $82.5 \dagger$ \\
Dick Francis & 7.7 & 4.4 & 9.7 & 4.5 & $11.2^{*}$
\end{tabular}


APPENDIX A (Continued)

\begin{tabular}{|c|c|c|c|c|c|}
\hline Author & $\begin{array}{c}\text { Overall } \\
\text { Mean }\end{array}$ & Male & Female & $\begin{array}{l}\text { Lo } \\
\text { PPVT }\end{array}$ & $\begin{array}{c}\mathrm{Hi} \\
\text { PPVT }\end{array}$ \\
\hline Stephen J. Gould & 23.0 & 24.6 & 22.0 & 19.7 & 26.6 \\
\hline Andrew Greeley & 11.7 & 7.9 & 14.0 & 5.1 & $18.9 \dagger$ \\
\hline Frank Herbert & 15.7 & $26.3 \dagger$ & 9.1 & 5.7 & $26.6 t$ \\
\hline S. E. Hinton & 39.0 & 31.6 & $43.5^{*}$ & 26.8 & $52.4 \dagger$ \\
\hline Erica Jong & 13.7 & 11.4 & 15.1 & 3.2 & $25.2 \dagger$ \\
\hline Stephen King & 90.0 & 93.0 & 88.2 & 86.6 & $93.7 *$ \\
\hline Judith Krantz & 42.3 & 33.3 & $47.8^{*}$ & 28.0 & $58.0 t$ \\
\hline Louis L'Amour & 40.0 & $50.0 \dagger$ & 33.9 & 23.6 & $58.0+$ \\
\hline Robert Ludlum & 31.7 & $38.6^{*}$ & 27.4 & 16.6 & $48.3 t$ \\
\hline Colleen McCullough & 21.0 & 14.0 & $25.3^{*}$ & 16.6 & $25.9 *$ \\
\hline James Michener & 35.7 & 39.5 & 33.3 & 16.6 & $56.6 \dagger$ \\
\hline Tom Peters & 2.7 & $5.3^{*}$ & 1.1 & 1.3 & 4.2 \\
\hline Sylvia Porter & 15.3 & 11.4 & 17.7 & 10.2 & $21.0 \dagger$ \\
\hline William Safire & 7.7 & 10.5 & 5.9 & 3.8 & $11.9 \dagger$ \\
\hline Gail Sheehy & 5.0 & 3.5 & 5.9 & 4.5 & 5.6 \\
\hline Sidney Sheldon & 70.0 & 66.7 & 72.0 & 58.0 & $83.2 \dagger$ \\
\hline Danielle Steel & 60.7 & 44.7 & $70.4 \dagger$ & 52.9 & $69.2+$ \\
\hline Studs Terkel & 7.7 & $14.0 \dagger$ & 3.8 & 1.3 & $14.7 \dagger$ \\
\hline Paul Theroux & 5.0 & 1.8 & $7.0^{*}$ & 2.5 & $7.7^{*}$ \\
\hline Alvin Toffler & 3.7 & 4.4 & 3.2 & 1.9 & 5.6 \\
\hline J. R. R. Tolkien & 62.0 & $71.1^{*}$ & 56.5 & 38.9 & $87.4 \dagger$ \\
\hline Irving Wallace & 30.3 & 31.6 & 29.6 & 23.6 & $37.8+$ \\
\hline Alice Walker & 33.7 & 30.7 & 35.5 & 26.8 & $41.3 \dagger$ \\
\hline Joseph Wambaugh & 7.7 & 7.9 & 7.5 & 1.3 & $14.3 \dagger$ \\
\hline Tom Wolfe & 32.7 & $40.4^{*}$ & 28.0 & 24.2 & $42.0 \dagger$ \\
\hline Bob Woodward & 24.3 & $35.1+$ & 17.7 & 14.0 & $35.7 \dagger$ \\
\hline
\end{tabular}

${ }^{*} p<.05 \quad \dagger p<.01$.

APPENDIX $B$

Percentage Recognition of Magazines on the MRT

\begin{tabular}{|c|c|c|c|c|c|}
\hline Magazine & $\begin{array}{c}\text { Overall } \\
\text { Mean }\end{array}$ & Male & Female & $\begin{array}{l}\text { Lo } \\
\text { PPVT }\end{array}$ & $\begin{array}{c}\mathrm{Hi} \\
\text { PPVT }\end{array}$ \\
\hline Analog Science Fiction & 7.0 & $11.4^{*}$ & 4.3 & 3.2 & $11.2 \dagger$ \\
\hline Architectural Digest & 45.3 & $52.6^{*}$ & 40.9 & 29.9 & $62.2 \dagger$ \\
\hline Atlantic & 34.7 & $43.9 \dagger$ & 29.0 & 24.8 & $45.5 \dagger$ \\
\hline Business Week & 73.0 & 77.2 & 70.4 & 70.1 & 76.2 \\
\hline Byte & 40.7 & $56.1+$ & 31.2 & 27.4 & $55.2 \dagger$ \\
\hline Car and Driver & 58.7 & $86.8 \dagger$ & 41.4 & 45.9 & $72.7+$ \\
\hline Changing Times & 20.7 & 21.1 & 20.4 & 16.6 & 25.2 \\
\hline Consumer Reports & 80.3 & 80.7 & 80.1 & 75.8 & $85.3^{*}$ \\
\hline Discover & 79.0 & $86.0^{*}$ & 74.7 & 78.3 & 79.7 \\
\hline Down Beat & 3.7 & 4.4 & 3.2 & 2.5 & 4.9 \\
\hline Ebony & 80.0 & 85.1 & 76.9 & 70.7 & $90.2 \dagger$ \\
\hline Esquire & 83.0 & $90.4 \dagger$ & 78.5 & 71.3 & $95.8 \dagger$ \\
\hline Field \& Stream & 62.7 & $76.3 \dagger$ & 54.3 & 47.1 & $79.7 \dagger$ \\
\hline Forbes & 74.7 & $90.4 \dagger$ & 65.1 & 61.1 & $89.5 \dagger$ \\
\hline Gentlemen's Quarterly & 67.3 & $80.7 \dagger$ & 59.1 & 54.8 & $81.1+$ \\
\hline Harper's Magazine & 55.0 & 54.4 & 55.4 & 42.0 & $69.2 \dagger$ \\
\hline House \& Garden & 56.7 & 51.8 & 59.7 & 52.9 & 60.8 \\
\hline Jet & 42.7 & $55.3 \dagger$ & 34.9 & 35.7 & $50.3^{*}$ \\
\hline Ladies Home Journal & 54.7 & 41.2 & $62.9 t$ & 38.9 & $72.0 \div$ \\
\hline Mademoiselle & 89.0 & 83.3 & $92.5^{*}$ & 84.7 & 93.7* \\
\hline McCall's & 81.7 & 74.6 & $86.0^{*}$ & 71.3 & $93.0 \dagger$ \\
\hline Mother Earth News & 7.7 & 7.9 & 7.5 & 7.0 & 8.4 \\
\hline Mother Jones & 12.0 & 16.7 & 9.1 & 3.8 & $21.0+$ \\
\hline Motor Trend & 56.7 & $80.7 \dagger$ & 41.9 & 44.6 & $69.9+$ \\
\hline New Republic & 18.7 & 23.7 & 15.6 & 9.6 & $28.7 \dagger$ \\
\hline
\end{tabular}


APPENDIX B (Continued)

\begin{tabular}{lccccc}
\hline \multicolumn{1}{c}{ Magazine } & $\begin{array}{c}\text { Overall } \\
\text { Mean }\end{array}$ & Male & Female & $\begin{array}{c}\text { Lo } \\
\text { PPVT }\end{array}$ & $\begin{array}{c}\text { Hi } \\
\text { PPVT }\end{array}$ \\
\hline New Yorker & 63.7 & $75.4 \dagger$ & 56.5 & 49.0 & $79.7 \dagger$ \\
Newsweek & 97.0 & 97.4 & 96.8 & 95.5 & 98.6 \\
Omni & 78.3 & $89.5 \dagger$ & 71.5 & 64.3 & $93.7 \dagger$ \\
Personal Computing & 19.7 & $32.5 \dagger$ & 11.8 & 13.4 & $26.6 \dagger$ \\
Popular Science & 65.7 & 71.1 & 62.4 & 61.1 & 70.6 \\
Psychology Today & 74.0 & 76.3 & 72.6 & 68.8 & $79.7^{*}$ \\
Redbook & 71.3 & 61.4 & $77.4 \dagger$ & 66.2 & $76.9^{*}$ \\
Road \& Track & 44.3 & $70.2 \dagger$ & 28.5 & 38.9 & $50.3^{*}$ \\
Rolling Stone & 94.3 & 93.9 & 94.6 & 91.1 & $97.9^{*}$ \\
Scientific American & 43.0 & $60.5 \dagger$ & 32.3 & 27.4 & $60.1 \dagger$ \\
Seventeen & 94.0 & 88.6 & $97.3 \dagger$ & 91.7 & 96.5 \\
Sports Dlustrated & 99.0 & 99.1 & 98.9 & 98.7 & 99.3 \\
The Sporting News & 30.0 & $63.2 \dagger$ & 9.7 & 21.7 & $39.2 \dagger$ \\
Town \& Country & 54.7 & 49.1 & 58.1 & 46.5 & $63.6 \dagger$ \\
Travel \& Leisure & 15.3 & 8.8 & $19.4^{*}$ & 14.6 & 16.1 \\
\hline${ }^{*} p<$ 05 $\dagger p<.01$ & & & & &
\end{tabular}

${ }^{*} p<.05 \quad+p<.01$.

APPENDIX C

Intercorrelations Involving Items on the Reading Questionnaire

\begin{tabular}{lrrrrrrrrr}
\hline \multicolumn{1}{c}{ Variable } & 1 & 2 & 3 & 4 & 5 & 6 & 7 & 8 & 9 \\
\hline 1 Multiple choice "read for pleasure" & & & & & & & & & \\
2 Multiple choice "read books" & .49 & & & & & & & \\
3 Multiple choice "magazines" & .23 & .08 & & & & & & \\
4 Multiple choice "newspapers" & .13 & -.04 & .15 & & & & & \\
5 Magazine subscriptions & .07 & .07 & .42 & .09 & & & & & \\
6 Favorite-author question & .19 & .32 & .01 & .07 & .08 & & & & \\
7 ART & .27 & .35 & .15 & .08 & .06 & .44 & & & \\
8 MRT & .18 & .20 & .20 & .18 & .05 & .38 & .64 & & \\
9 Activity preference-reading & .41 & .62 & .04 & -.10 & -.05 & .31 & .42 & .21 & \\
10 PPVT & .16 & .24 & .09 & .00 & -.01 & .35 & .64 & .57 & .31 \\
\hline
\end{tabular}

Note-Correlations greater than .12 in absolute value are significant at the .05 level. Correlations greater than .15 in absolute value are significant at the .01 level.

(Manuscript received April 19, 1991;

revision accepted for publication July 26, 1991.) 